\title{
Nonlinear Adaptive Dynamic Output-Feedback Power-Level Control of Nuclear Heating Reactors
}

\author{
Zhe Dong \\ Key Laboratory of Advanced Reactor Engineering and Safety of Ministry of Education, Institute of Nuclear and New Energy Technology \\ of Tsinghua University, Beijing 100084, China
}

Correspondence should be addressed to Zhe Dong; dongzhe@mail.tsinghua.edu.cn

Received 24 April 2013; Accepted 1 July 2013

Academic Editor: Hiroshi Sekimoto

Copyright (C) 2013 Zhe Dong. This is an open access article distributed under the Creative Commons Attribution License, which permits unrestricted use, distribution, and reproduction in any medium, provided the original work is properly cited.

Due to the high safety performance of small nuclear reactors, there is a promising future for small reactors. Nuclear heating reactor (NHR) is a small reactor that has many advanced safety features such as the integrated arrangement, natural circulation at any power levels, self-pressurization, hydraulic control rod driving, and passive residual heating removing and can be applied to the fields of district heating, seawater desalination, and electricity production. Since the NHR dynamics has strong nonlinearity and uncertainty, it is meaningful to develop the nonlinear adaptive power-level control technique. From the idea of physically based control design method, a novel nonlinear adaptive power-level control is given for the NHR in this paper. It is theoretically proved that this newly built controller does not only provide globally asymptotic closed-loop stability but is also adaptive to the system uncertainty. Numerical simulation results show the feasibility of this controller and the relationship between the performance and controller parameters.

\section{Introduction}

Due to the serious climate and environment problems such as global warming that caused by those greenhouse gases emitted from burning fossil fuels, it is significant for people to develop clean energy. Nuclear energy is one of the most rapidly developing clean energy, which gives the current rebirth of nuclear energy industry. After the severe Fukushima nuclear accident, much more attention has to be drawn on safety issues of nuclear plants. In contrast to those large nuclear reactors, small reactors usually has low power density which leads to higher safety performance and can be built near big cities for district heating, seawater desalination, and electricity production. Nuclear heating reactor (NHR) is a kind of small light water reactor, and the design of the NHR in China started since early 1980s. The first NHR of China, that is, the $5 \mathrm{MWth}$ test nuclear heating reactor (NHR5) began to be built in the Institute of Nuclear and New Energy Technology (INET) of Tsinghua University in March 1986 and reached its full power operation on December 16, 1989 [1-4]. Based on NHR-5, INET also designed the 200 MWth nuclear heating reactor NHR-200 which inherits many advanced safety characteristics from NHR- 5 such as integrated arrangement, natural circulation at any operating power levels, self-pressurized performance, hydraulic control rod driver, and passive residual heat removing [5]. Both structure and cross-section of the NHR-200 are shown in Figure 1. As an improvement of the NHR-5, the NHR-200 can be applied to not only the areas of district heating, system [5] and seawater desalination [6] but also small-scale power generation for those consumers which are isolated from the central power grids. INET also gave some results on the interconnection between NHR and some desalination processes $[7,8]$. Since the NHR can be used for electricity production, district heating, and seawater desalination, the load of the NHR may vary frequently in a wide range, and its power controller should provide the load-following performance.

The basic principle of power-level control is generating the insertion and withdrawal speed of control rods in order to regulate power output at a demand value using the average temperature deviation of the coolant inside the reactor core and power mismatch of the reactor. Power-level control is one of the most crucial techniques guaranteeing safe, 


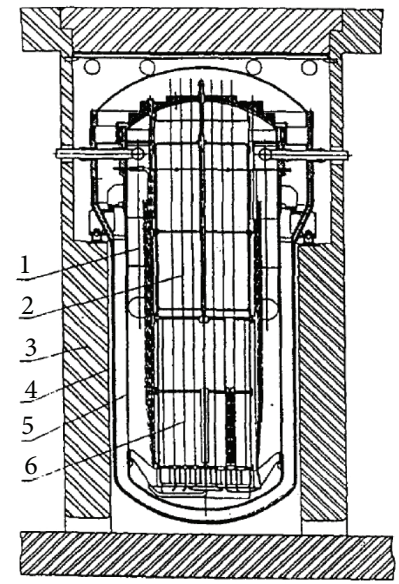

(a)

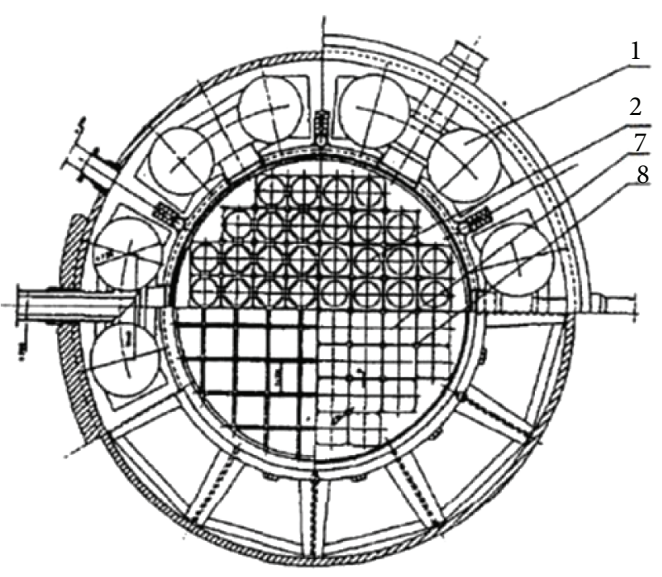

(b)

FIGURE 1: Structure and cross-section of the NHR-200: 1: primary heating exchanger, 2: riser, 3: biological shield, 4: containment, 5: pressure vessel, 6: core, 7: fuel elements, 8: control rods.

stable, and efficient operation. With the development of high performance industrial microprocessors, it is now possible to implement advanced control laws for improving dynamic performance of nuclear reactors. Edwards designed a linear power-level control strategy named state-feedback assisted classical controller (SFAC) [9] which modifies reference signal of an embedded classical output feedback controller by state feedback and is easy to be implemented since it leaves the current classical feedback loop in place. Then, the technique of linear quadratic Gaussian regulation with the loop transfer recovery (LQG/LTR) was then applied to strengthen the robustness of the SFAC $[10,11]$. Since nuclear reactors are essentially complex and nonlinear dynamic systems, it is necessary and meaningful to develop nonlinear powerlevel control strategy for guaranteeing the load following performance. Shtessel gave a nonlinear power-level control composed of a static state-feedback sliding mode control and a sliding mode state-observer for space nuclear reactor TOPAZ II [12]. Dong presented a dynamic output feedback dissipation controller [13] based on both backstepping technique [14] and dissipation-based high gain filter (DHGF) $[15,16]$. Though these nonlinear controllers provide both globally asymptotic closed-loop stability and load-following performance, they are too complicated to be implemented practically. Nowadays, designing effective control by fully using the good features of natural system dynamics, that is, the physically based control method [17-19], has already become a hot spot of modern control theory. Since every nuclear reactor is essentially a thermodynamic system with the nuclear fission reaction whose evolution trend is given by the differences of both temperature and concentration but not energy, the existing physically based method cannot be applied directly. Based upon defining the shifted-ectropy for the modular high temperature gas-cooled reactor (MHTGR) [20], Dong gave a physically based power-level control for the MHTGR [21] which provides globally asymptotic closed-loop stability and takes a simple form. Since every nuclear reactor is actually an uncertain dynamic system, it is very meaningful to design the adaptive power-level control law. Actually, adaptive output-feedback control of nonlinear systems is also a hot area in control theory and has also been applied to some practical systems. Fu presented a dynamic output feedback adaptive control law for nonlinear systems in generalized output feedback canonical form based on the extended backstepping approach [22]. Yang et al. gave an adaptive robust output feedback nonlinear control for magnetic levitation system by merging a disturbance observer into the K-filterbased adaptive control design technique [23]. Mackunis et al. developed an adaptive output dynamic inversion control for an unmanned aerial vehicle (UAV) which guarantees global asymptotic tracking performance [24]. Xu and Huang gave a global robust adaptive output feedback control for a class of uncertain nonlinear systems based on the internal mode design approach [25]. Yao et al. proposed an adaptive precision motion control for a high-speed industrial gantry by the desired compensation adaptive robust control (DCARC) approach [26]. Since nuclear energy systems have their own dynamic features, the above adaptive output feedback control design methods cannot fully use the subdynamics of nuclear energy systems that is beneficial to stabilization and may lead to control laws with complicated forms that are hard to implement. Therefore, design adaptive power-level control strategies by the use of the good parts of nuclear energy system dynamics is very meaningful. Park and Cho gave a PI power-level control law with feedback gains adjusted by an adaptive law [27]. Arab-Alibeik and Setayeshi designed an adaptive power-level control by using a feedforward neural network [28] for the pressurized water reactor (PWR), and the neural network is trained online. Dong proposed a novel nonlinear adaptive power-level controller which provides not only the globally asymptotic closed-loop stability but also the adaption capability to system uncertainties [29].

With comparison to the common PWRs, the feature of natural circulation at any power-levels strengthen the nonlinearity of the NHR dynamics. Moreover, there must be modeling uncertainty and exterior disturbance. Thus, to guarantee 
the load following performance, it is quite meaningful to develop nonlinear adaptive power-level control strategy for the NHR. In this paper, a dynamic output-feedback nonlinear adaptive power-level control law is presented for the NHR through the physically based approach. This new powerlevel control guarantees load-following performance through providing both the globally asymptotic closed-loop stability and the adaption capability to slowly varying uncertainty. This newly built control is then applied to the power-level regulation of a NHR, and numerical simulation results show both its feasibility and the relationship between its control performance and values of controller parameters.

\section{Problem Formulation}

In this section, the nonlinear state-space model for designing the power-level control strategy is firstly given, and then the theoretic problem corresponding to the control design is established.

2.1. Nonlinear State-Space Model. The reactor dynamics adopted here for power-level control design is the point kinetics with one equivalent delayed neutron group and the reactivity feedback determined by the variations of average temperatures of the fuel and coolant, which is given as follows:

$$
\begin{gathered}
\dot{n}_{\mathrm{r}}=\frac{1}{\Lambda}\left[\left(\rho_{\mathrm{r}}-\beta\right) n_{\mathrm{r}}+\beta c_{\mathrm{r}}\right. \\
\left.+\alpha_{\mathrm{f}} n_{\mathrm{r}}\left(T_{\mathrm{f}}-T_{\mathrm{f}, \mathrm{m}}\right)+\alpha_{\mathrm{c}} n_{\mathrm{r}}\left(T_{\mathrm{cav}}-T_{\mathrm{cav}, \mathrm{m}}\right)\right], \\
\dot{c}_{\mathrm{r}}=\lambda\left(n_{\mathrm{r}}-c_{\mathrm{r}}\right), \\
\dot{T}_{\mathrm{f}}=\frac{1}{\mu_{\mathrm{f}}}\left[-\Omega\left(T_{\mathrm{f}}-T_{\mathrm{cav}}\right)+P_{0} n_{\mathrm{r}}\right], \\
\dot{T}_{\mathrm{cav}}=\frac{1}{\mu_{\mathrm{c}}}\left[\Omega\left(T_{\mathrm{f}}-T_{\mathrm{cav}}\right)-2 M\left(T_{\mathrm{cav}}-T_{\mathrm{cin}}\right)\right], \\
\dot{\rho}_{\mathrm{r}}=G_{\mathrm{r}} z_{\mathrm{r}},
\end{gathered}
$$

where $n_{\mathrm{r}}$ is the relative nuclear power, $c_{\mathrm{r}}$ is the relative concentration of delayed neutron precursor, $\beta$ is the fraction of delayed neutrons, $\Lambda$ is the effective prompt neutron lifetime, $\lambda$ is the effective radioactive decay constant of delayed neutron precursor, $\alpha_{\mathrm{f}}$ and $\alpha_{\mathrm{c}}$ are, respectively, the reactivity coefficients of the fuel and coolant temperatures, $T_{\mathrm{f}}$ is the average fuel temperature, $T_{\text {cav }}$ and $T_{\text {cin }}$ are, respectively, the average temperature of the coolant inside the core and the temperature of the coolant entering the core, $T_{\text {cav, } m}$ and $T_{\text {cin,m }}$ are, respectively, the initial equilibrium values of $T_{\text {cav }}$ and $T_{\text {cin }}$, $\Omega$ is the heat transfer coefficient between fuel and coolant, $M$ is the mass flow rate times heat capacity of the coolant, $P_{0}$ is the rated power level, $\rho_{\mathrm{r}}$ is the reactivity due to the control rods, $\mu_{\mathrm{f}}$ is the total heat capacity of the fuel, $\mu_{\mathrm{c}}$ is the total heat capacity of the reactor coolant, $G_{\mathrm{r}}$ is the total reactivity worth of control rods, and $z_{\mathrm{r}}$ is the control input, that is, the speed signal of control rods.
Suppose that $n_{\mathrm{r} 0}, c_{\mathrm{r} 0}, T_{\mathrm{f} 0}, T_{\mathrm{cav} 0}, T_{\mathrm{cin} 0}$, and $\rho_{\mathrm{r} 0}$ are, respectively, the steady values of $n_{\mathrm{r}}, c_{\mathrm{r}}, T_{\mathrm{f}}, T_{\text {cav }}, T_{\text {cin }}$, and $\rho_{\mathrm{r}}$, which satisfies

$$
\dot{n}_{\mathrm{r} 0}=\dot{c}_{\mathrm{r} 0}=\dot{T}_{\mathrm{f} 0}=\dot{T}_{\mathrm{cav} 0}=\dot{T}_{\mathrm{cin} 0}=\dot{\rho}_{\mathrm{r} 0}=0 .
$$

From (1) and (2), we can easily see that these steady values should satisfy

$$
\begin{gathered}
n_{\mathrm{r} 0}=c_{\mathrm{r} 0}, \\
\rho_{\mathrm{r} 0}=-\alpha_{\mathrm{f}}\left(T_{\mathrm{f} 0}-T_{\mathrm{f}, \mathrm{m}}\right)-\alpha_{\mathrm{c}}\left(T_{\mathrm{cav} 0}-T_{\mathrm{cav}, \mathrm{m}}\right), \\
P_{0} n_{\mathrm{r} 0}=\Omega\left(T_{\mathrm{f} 0}-T_{\mathrm{cav} 0}\right)=2 M\left(T_{\mathrm{cav} 0}-T_{\mathrm{cin} 0}\right) .
\end{gathered}
$$

Define the deviations between the actual and the steady values of $n_{\mathrm{r}}, c_{\mathrm{r}}, T_{\mathrm{f}}, T_{\text {cav }}, T_{\text {cin }}$, and $\rho_{\mathrm{r}}$ as

$$
\begin{gathered}
\delta n_{\mathrm{r}}=n_{\mathrm{r}}-n_{\mathrm{r} 0}, \\
\delta c_{\mathrm{r}}=c_{\mathrm{r}}-c_{\mathrm{r} 0}, \\
\delta T_{\mathrm{f}}=T_{\mathrm{f}}-T_{\mathrm{f} 0}, \\
\delta T_{\mathrm{cav}}=T_{\mathrm{cav}}-T_{\mathrm{cav} 0}, \\
\delta \rho_{\mathrm{r}}=\rho_{\mathrm{r}}-\rho_{\mathrm{r} 0}, \\
\delta T_{\mathrm{cin}}=T_{\mathrm{cin}}-T_{\text {cin } 0} .
\end{gathered}
$$

Then, based upon (3), dynamic model (1) can be rewritten as

$$
\begin{gathered}
\delta \dot{n}_{\mathrm{r}}=\frac{1}{\Lambda}\left[-\beta\left(\delta n_{\mathrm{r}}-\delta c_{\mathrm{r}}\right)+n_{\mathrm{r}}\left(\alpha_{\mathrm{f}} \delta T_{\mathrm{f}}+\alpha_{\mathrm{c}} \delta T_{\mathrm{cav}}+\delta \rho_{\mathrm{r}}\right)\right] \\
\delta \dot{c}_{\mathrm{r}}=\lambda\left(\delta n_{\mathrm{r}}-\delta c_{\mathrm{r}}\right), \\
\delta \dot{T}_{\mathrm{f}}=\frac{1}{\mu_{\mathrm{f}}}\left[-\Omega\left(\delta T_{\mathrm{f}}-\delta T_{\mathrm{cav}}\right)+P_{0} \delta n_{\mathrm{r}}\right], \\
\delta \dot{T}_{\mathrm{cav}}=\frac{1}{\mu_{\mathrm{c}}}\left[\Omega\left(\delta T_{\mathrm{f}}-\delta T_{\mathrm{cav}}\right)-2 M\left(\delta T_{\mathrm{cav}}-\delta T_{\mathrm{cin}}\right)\right] \\
\delta \dot{\rho}_{\mathrm{r}}=G_{\mathrm{r}} z_{\mathrm{r}} .
\end{gathered}
$$

It is worth to be noted here that the physical parameters, $\beta, \Lambda, \Omega, M, \mu_{\mathrm{f}}$, and $\mu_{\mathrm{c}}$ cannot be obtained accurately, which results in parameter uncertainty. Seeing $\delta T_{\text {din }}$ as an exterior disturbance also leads to uncertainty. Furthermore, there must exist uncertainty which comes from unmodeled dynamics. Based on this discussion, the nonlinear state-space model is

$$
\begin{gathered}
\dot{\mathbf{x}}=\mathbf{f}(\mathbf{x})+\mathbf{g}(\mathbf{x}) \xi+\boldsymbol{\sigma}, \\
\dot{\xi}=u,
\end{gathered}
$$


where

$$
\begin{aligned}
& \mathbf{x}=\left[\begin{array}{llll}
\delta n_{\mathrm{r}} & \delta c_{\mathrm{r}} & \delta T_{\mathrm{f}} & \delta T_{\mathrm{cav}}
\end{array}\right]^{\mathrm{T}}, \\
& \xi=\delta \rho_{\mathrm{r}}, \\
& u=G_{\mathrm{r}} z_{\mathrm{r}}, \\
& \sigma=\left[\begin{array}{llll}
\sigma_{1} & \sigma_{2} & \sigma_{3} & \sigma_{4}
\end{array}\right]^{\mathrm{T}}, \\
& \mathbf{f}(\mathbf{x})=\left[\begin{array}{c}
-\frac{\beta}{\Lambda}\left(x_{1}-x_{2}\right)+\frac{n_{\mathrm{r} 0}+x_{1}}{\Lambda}\left(\alpha_{\mathrm{f}} x_{3}+\alpha_{\mathrm{c}} x_{4}\right) \\
\lambda\left(x_{1}-x_{2}\right) \\
-\frac{\Omega}{\mu_{\mathrm{f}}}\left(x_{3}-x_{4}\right)+\frac{P_{0}}{\mu_{\mathrm{f}}} x_{1} \\
\frac{\Omega}{\mu_{\mathrm{c}}}\left(x_{3}-x_{4}\right)-\frac{2 M}{\mu_{\mathrm{c}}} x_{4}
\end{array}\right], \\
& \mathbf{g}(\mathbf{x})=\left[\begin{array}{llll}
\frac{n_{\mathrm{r} 0}+x_{1}}{\Lambda} & 0 & 0 & 0
\end{array}\right]^{\mathrm{T}} .
\end{aligned}
$$

Here $\boldsymbol{\sigma} \in R^{4}$ is a norm-bounded vector denoting the uncertainty. Both $\mathbf{x}$ and $\xi$ are the system state, and $u$ is the control input.

2.2. Formulation of Theoretic Problem. If $x_{1} \equiv 0$, then from the first two equations of model (6), we have

$$
\begin{gathered}
\beta x_{2}+n_{\mathrm{r} 0}\left(\alpha_{\mathrm{f}} x_{3}+\alpha_{\mathrm{c}} x_{4}+\xi\right)+\sigma_{1} \equiv 0, \\
\dot{x}_{2}=-\lambda x_{2}+\sigma_{2} .
\end{gathered}
$$

It is easy to see from (14) that

$$
x_{2}=x_{20} e^{-\lambda t}+\int_{t_{0}}^{t} e^{-\lambda(t-s)} \sigma_{2}(s) \mathrm{d} s,
$$

where $x_{20}$ is the initial value of $x_{2}$. Substitute (15) to (13),

$$
\begin{aligned}
& \beta x_{20} e^{-\lambda t}+\beta \int_{t_{0}}^{t} e^{-\lambda(t-s)} \sigma_{2}(s) \mathrm{d} s \\
& \quad+n_{\mathrm{r} 0}\left(\alpha_{\mathrm{f}} x_{3}+\alpha_{\mathrm{c}} x_{4}\right)+\left(n_{\mathrm{r} 0} \xi+\sigma_{1}\right) \equiv 0 .
\end{aligned}
$$

Since values of real scalars $\sigma_{1}, \sigma_{2}, x_{20}, \xi$ are all arbitrary, (16) is satisfied if and only if

$$
x_{2}=\sigma_{2}=\alpha_{\mathrm{f}} x_{3}+\alpha_{\mathrm{c}} x_{4}=n_{\mathrm{r} 0} \xi+\sigma_{1} \equiv 0 .
$$

Moreover, from (17) and the second two equations of model (6), we can easily derive that

$$
\begin{array}{r}
-\frac{\alpha_{\mathrm{f}} \Omega}{\mu_{\mathrm{f}}}\left(x_{3}-x_{4}\right)+\alpha_{\mathrm{f}} \sigma_{3}+\frac{\alpha_{\mathrm{c}} \Omega}{\mu_{\mathrm{c}}}\left(x_{3}-x_{4}\right) \\
-\frac{2 M \alpha_{\mathrm{c}}}{\mu_{\mathrm{c}}} x_{4}+\alpha_{\mathrm{c}} \sigma_{4}=\alpha_{\mathrm{f}} \dot{x}_{3}+\alpha_{\mathrm{c}} \dot{x}_{4} \equiv 0,
\end{array}
$$

that is

$$
-\left[\Omega\left(\frac{\alpha_{\mathrm{c}}}{\mu_{\mathrm{c}}}-\frac{\alpha_{\mathrm{f}}}{\mu_{\mathrm{f}}}\right)\left(1+\frac{\alpha_{\mathrm{c}}}{\alpha_{\mathrm{f}}}\right)+\frac{2 M \alpha_{\mathrm{c}}}{\mu_{\mathrm{c}}}\right] x_{4}+\alpha_{\mathrm{f}} \sigma_{3}+\alpha_{\mathrm{c}} \sigma_{4} \equiv 0 .
$$

Since both $\sigma_{3}$ and $\sigma_{4}$ are arbitrary real scalars, it is clear that (19) holds if and only if

$$
x_{4}=\sigma_{3}=\sigma_{4} \equiv 0 .
$$

Based on (17) and (20), we can see that if $x_{1} \equiv 0$, then

$$
\sigma_{2}=\sigma_{3}=\sigma_{4} \equiv 0 \text {. }
$$

Thus, from (21),

$$
\begin{gathered}
n_{\mathrm{r}}=n_{\mathrm{r} 0}+x_{1}>0, \\
c_{\mathrm{r}}=c_{\mathrm{r} 0}+x_{2}=n_{\mathrm{r} 0}+x_{2}>0,
\end{gathered}
$$

it is reasonable to let $\sigma$ be

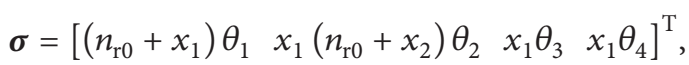

where

$$
\left|\theta_{i}\right| \leq M_{i}, \quad i=1, \ldots, 4,
$$

and $M_{i}(i=1,2,3,4)$ are all given positive scalars.

There might be other forms of $\boldsymbol{\sigma}$ that satisfy the property. However, (23) is reasonable with simple form. Based upon the above derivation and analysis, the theoretic problem to be solved in this paper can be formed as follows.

Problem 1. Consider uncertain nonlinear system (6). How to design control input $u$ so that the closed-loop system is not only globally asymptotically stable but also adaptive to uncertainty $\boldsymbol{\sigma}$ that takes the form of (23)?

\section{Nonlinear Adaptive Power-Level Control Design}

In this part, Problem 1 which is raised at the end of Section 2 will be solved step by step through establishing the nonlinear adaptive power-level control law for the NHR.

3.1. State-Feedback Control Design. Due to the idea of backstepping method for nonlinear control law design, $\xi$ can be regarded as a virtual control, and the first step is to design its referenced value $\xi_{\text {r }}$ that stabilizes subsystem

$$
\dot{\mathbf{x}}=\mathbf{f}(\mathbf{x})+\mathbf{g}(\mathbf{x}) \xi+\boldsymbol{\sigma},
$$

where vector-valued functions $\mathbf{f}, \mathbf{g}$, and $\boldsymbol{\sigma}$ are determined by (11), (12), and (23), respectively.

Theorem 2 gives a nonlinear adaptive state-feedback stabilizer for subsystem (25), which is the first main result of this paper.

Theorem 2. Consider subsystem (25), and assume that uncertain parameters $\theta_{i}(i=1, \ldots, 4)$ vary slowly, that is,

$$
\dot{\theta} \gg \mathrm{O},
$$

where

$$
\boldsymbol{\theta}=\left[\begin{array}{llll}
\theta_{1} & \theta_{2} & \theta_{3} & \theta_{4}
\end{array}\right]^{\mathrm{T}} \text {. }
$$


Consider state-feedback adaptive virtual control law

$$
\xi_{\mathrm{r}}=-k_{\mathrm{n}} x_{1}-k_{\mathrm{f}} x_{3}-k_{\mathrm{c}} x_{4}-\widehat{\boldsymbol{\theta}}^{\mathrm{T}} \boldsymbol{\Gamma} \boldsymbol{\omega}
$$

where positive scalars $k_{\mathrm{n}}, k_{\mathrm{f}}$ and $k_{\mathrm{c}}$ are all feedback gains and $\widehat{\boldsymbol{\theta}}$ is the estimation of $\boldsymbol{\theta}$ satisfying

$$
\widehat{\boldsymbol{\theta}}=\left[\begin{array}{llll}
\widehat{\theta}_{1} & \widehat{\theta}_{2} & \widehat{\theta}_{3} & \widehat{\theta}_{4}
\end{array}\right]^{\mathrm{T}}
$$

and determined by adaptive law

$$
\begin{gathered}
\dot{\hat{\boldsymbol{\theta}}}=x_{1} \mathbf{Q}^{-1} \boldsymbol{\omega}, \\
k_{\mathrm{c}}=\frac{\Omega \mu_{\mathrm{c}}}{(M+\Omega) \mu_{\mathrm{f}}}\left(k_{\mathrm{f}}-\alpha_{\mathrm{f}}\right)+\alpha_{\mathrm{c}}, \\
\boldsymbol{\omega}=\left[\begin{array}{lll}
1 & x_{2}\left(1+\frac{\Omega}{M}\right) x_{3}+\frac{\Omega \mu_{\mathrm{c}}}{M \mu_{\mathrm{f}}} x_{4} & \frac{\Omega}{M} x_{3}+\left(1+\frac{\Omega}{M}\right) x_{4}
\end{array}\right]_{(32)}^{\mathrm{T}}, \\
\Gamma=\operatorname{diag}\left(\left[\begin{array}{lll}
\Lambda \frac{\beta}{\lambda} \frac{k_{\mathrm{f}}^{\prime} \mu_{\mathrm{f}}}{(1+\Omega / M) P_{0}} & \frac{k_{\mathrm{f}}^{\prime} \mu_{\mathrm{c}}}{(1+\Omega / M) P_{0}}
\end{array}\right]^{\mathrm{T}}\right), \\
\mathbf{Q}=\operatorname{diag}\left(\left[\begin{array}{llll}
q_{1} & q_{2} & q_{3} & q_{4}
\end{array}\right]\right), \quad q_{i}>0, i=1, \ldots, 4 .
\end{gathered}
$$

Adaptive virtual control strategy (28) guarantees globally asymptotic closed-loop stability for sub-system (25), if $k_{\mathrm{f}}^{\prime}$ is a positive scalar.

Proof. Based upon the shifted-ectropy for nuclear reactors [19], the Lyapunov function of the neutron kinetics can be chosen as

$$
\begin{aligned}
\zeta_{\mathrm{N}}\left(x_{1}, x_{2}\right)= & \Lambda\left[1+\frac{x_{1}}{n_{\mathrm{r} 0}}-\ln \left(1+\frac{x_{1}}{n_{\mathrm{r} 0}}\right)\right] \\
& +\frac{\beta}{\lambda}\left[1+\frac{x_{2}}{n_{\mathrm{r} 0}}-\ln \left(1+\frac{x_{2}}{n_{\mathrm{r} 0}}\right)\right] .
\end{aligned}
$$

It is clear that $\zeta_{\mathrm{N}}$ is positive definite, and differentiation satisfies

$$
\begin{aligned}
\dot{\zeta}_{\mathrm{N}}= & -\frac{\beta\left(x_{1}-x_{2}\right)^{2}}{n_{\mathrm{r} 0}\left(n_{\mathrm{r} 0}+x_{1}\right)\left(n_{\mathrm{r} 0}+x_{2}\right)} \\
& +\frac{x_{1}}{n_{\mathrm{r} 0}}\left(\alpha_{\mathrm{f}} x_{3}+\alpha_{\mathrm{c}} x_{4}+\xi_{\mathrm{r}}\right) \\
& +\frac{x_{1}}{n_{\mathrm{r} 0}}\left(\Lambda \theta_{1}+\frac{\beta}{\lambda} x_{2} \theta_{2}\right) .
\end{aligned}
$$

Substitute (28) to (37), and we have

$$
\begin{aligned}
\dot{\zeta}_{\mathrm{N}}= & -\frac{\beta\left(x_{1}-x_{2}\right)^{2}}{n_{\mathrm{r} 0}\left(n_{\mathrm{r} 0}+x_{1}\right)\left(n_{\mathrm{r} 0}+x_{2}\right)} \\
& -\frac{k_{\mathrm{n}}}{n_{\mathrm{r} 0}} x_{1}^{2}-\frac{x_{1}}{n_{\mathrm{r} 0}}\left(k_{\mathrm{f}}^{\prime} x_{3}+k_{\mathrm{c}}^{\prime} x_{4}\right) \\
& -\frac{x_{1}}{n_{\mathrm{r} 0}} \boldsymbol{\omega}^{\mathrm{T}} \boldsymbol{\Gamma} \hat{\boldsymbol{\theta}}+\frac{x_{1}}{n_{\mathrm{r} 0}}\left(\Lambda \theta_{1}+\frac{\beta}{\lambda} x_{2} \theta_{2}\right),
\end{aligned}
$$

where

$$
k_{\mathrm{c}}^{\prime}=k_{\mathrm{c}}-\alpha_{\mathrm{c}} .
$$

Moreover, choose the Lyapunov function for the reactor thermal-hydraulic loop as

$$
\zeta_{\mathrm{T}}\left(x_{3}, x_{4}\right)=\frac{1}{2} \mu_{\mathrm{f}} x_{3}^{2}+\frac{1}{2} \mu_{\mathrm{c}} x_{4}^{2}+\frac{\Omega}{2 M \mu_{\mathrm{f}}}\left(\mu_{\mathrm{f}} x_{3}+\mu_{\mathrm{c}} x_{4}\right)^{2},
$$

where the first and second terms of $\zeta_{\mathrm{T}}$ are, respectively, the shifted-ectropy of the fuel and the coolant, and the third term is the shifted-ectropy of the total thermal-hydraulic loop. Differentiate $\zeta_{\mathrm{T}}$ along the trajectory given by (25), and we can derive that

$$
\begin{aligned}
\dot{\zeta}_{\mathrm{T}}= & -\Omega\left(x_{3}-x_{4}\right)^{2}-2 M x_{4}^{2}+P_{0} x_{1} x_{3} \\
& +x_{1}\left(\mu_{\mathrm{f}} x_{3} \theta_{3}+\mu_{\mathrm{c}} x_{4} \theta_{4}\right)-\frac{\Omega}{M \mu_{\mathrm{f}}} \\
& \times\left\{\left[2 M \mu_{\mathrm{f}} x_{3} x_{4}-2 M \mu_{\mathrm{c}} x_{4}^{2}+P_{0} x_{1}\left(\mu_{\mathrm{f}} x_{3}+\mu_{\mathrm{c}} x_{4}\right)\right]\right. \\
& \left.+x_{1}\left(\mu_{\mathrm{f}} x_{3}+\mu_{\mathrm{c}} x_{4}\right)\left(\mu_{\mathrm{f}} \theta_{3}+\mu_{\mathrm{c}} \theta_{4}\right)\right\} \\
= & -\Omega x_{3}^{2}-\Omega\left(1+\frac{2 M}{\Omega}+\frac{2 \mu_{\mathrm{c}}}{\mu_{\mathrm{f}}}\right) x_{4}^{2} \\
& +P_{0} x_{1}\left[\left(1+\frac{\Omega}{M}\right) x_{3}+\frac{\Omega \mu_{\mathrm{c}}}{M \mu_{\mathrm{f}}} x_{4}\right] \\
& +\mu_{\mathrm{f}} x_{1}\left[\left(1+\frac{\Omega}{M}\right) x_{3}+\frac{\Omega \mu_{\mathrm{c}}}{M \mu_{\mathrm{f}}} x_{4}\right] \theta_{3} \\
& +\mu_{\mathrm{c}} x_{1}\left[\left(1+\frac{\Omega \mu_{\mathrm{c}}}{M \mu_{\mathrm{f}}}\right) x_{3}+\frac{\Omega}{M} x_{4}\right] \theta_{4} .
\end{aligned}
$$

Now, select the Lyapunov function for subsystem (25) as

$$
V_{1}(\mathbf{x})=n_{\mathrm{r} 0} \zeta_{\mathrm{T}}\left(x_{1}, x_{2}\right)+\frac{k_{\mathrm{f}}^{\prime}}{(1+\Omega / M) P_{0}} \zeta_{\mathrm{N}}\left(x_{3}, x_{4}\right),
$$

and we can easily see that $V_{1}$ is positive definite if and only if $k_{\mathrm{f}}^{\prime}$ is a positive scalar. Then, from (38) and (41), the differentiation of $V_{1}$ along the trajectory given by (25) and (28) can be represented as

$$
\begin{aligned}
\dot{V}_{1}(\mathbf{x})= & n_{\mathrm{r} 0} \dot{\zeta}_{\mathrm{T}}\left(x_{1}, x_{2}\right)+\frac{k_{\mathrm{f}}^{\prime}}{(1+\Omega / M) P_{0}} \dot{\zeta}_{\mathrm{N}}\left(x_{3}, x_{4}\right) \\
= & -\frac{\beta\left(x_{1}-x_{2}\right)^{2}}{\left(n_{\mathrm{r} 0}+x_{1}\right)\left(n_{\mathrm{r} 0}+x_{2}\right)}-k_{\mathrm{n}} x_{1}^{2} \\
& -\frac{k_{\mathrm{f}}^{\prime} \Omega}{(1+\Omega / M) P_{0}}\left[x_{3}^{2}+\left(1+\frac{2 M}{\Omega}+\frac{2 \mu_{\mathrm{c}}}{\mu_{\mathrm{f}}}\right) x_{4}^{2}\right] \\
& +k_{\mathrm{f}}^{\prime} x_{1}\left[x_{3}+\frac{\Omega \mu_{\mathrm{c}}}{(M+\Omega) \mu_{\mathrm{f}}} x_{4}-x_{1}\left(k_{\mathrm{f}}^{\prime} x_{3}+k_{\mathrm{c}}^{\prime} x_{4}\right)\right. \\
& -x_{1} \boldsymbol{\omega}^{\mathrm{T}} \boldsymbol{\Gamma} \widehat{\boldsymbol{\theta}}+x_{1}\left(\Lambda \theta_{1}+\frac{\beta}{\lambda} x_{2} \theta_{2}\right)+\frac{k_{\mathrm{f}}^{\prime} x_{1}}{(1+\Omega / M) P_{0}} \\
& \times\left\{\mu_{\mathrm{f}}\left[\left(1+\frac{\Omega}{M}\right) x_{3}+\frac{\Omega \mu_{\mathrm{c}}}{M \mu_{\mathrm{f}}} x_{4}\right] \theta_{3}\right. \\
& \left.+\mu_{\mathrm{c}}\left[\frac{\Omega}{M} x_{3}+\left(1+\frac{\Omega \mu_{\mathrm{c}}}{M \mu_{\mathrm{f}}}\right) x_{4}\right] \theta_{4}\right\} .
\end{aligned}
$$


From (31), (32), and (33), we have

$$
\begin{aligned}
\dot{V}_{1}(\mathbf{x})= & -\frac{\beta\left(x_{1}-x_{2}\right)^{2}}{\left(n_{\mathrm{r} 0}+x_{1}\right)\left(n_{\mathrm{r} 0}+x_{2}\right)}-k_{\mathrm{n}} x_{1}^{2}-\frac{k_{\mathrm{f}}^{\prime} \Omega}{(1+\Omega / M) P_{0}} \\
& \times\left[x_{3}^{2}+\left(1+\frac{2 M}{\Omega}+\frac{2 \mu_{\mathrm{c}}}{\mu_{\mathrm{f}}}\right) x_{4}^{2}\right]+x_{1} \tilde{\boldsymbol{\theta}}^{\mathrm{T}} \Gamma \boldsymbol{\omega},
\end{aligned}
$$

where

$$
\widetilde{\boldsymbol{\theta}}=\boldsymbol{\theta}-\widehat{\boldsymbol{\theta}}
$$

is the estimation error of uncertainty vector $\boldsymbol{\theta}$.

Choose the Lyapunov function for the closed-loop system formed by subsystem (25), virtual controller (28), and adaptive law (30) as

$$
\begin{aligned}
V_{2}(\mathbf{x}, \widetilde{\boldsymbol{\theta}})= & V_{1}(\mathbf{x})+\frac{1}{2} \widetilde{\boldsymbol{\theta}}^{\mathrm{T}} \mathbf{Q} \Gamma \widetilde{\boldsymbol{\theta}}=n_{\mathrm{r} 0} \zeta_{\mathrm{T}}\left(x_{1}, x_{2}\right) \\
& +\frac{k_{\mathrm{f}}^{\prime}}{(1+\Omega / M) P_{0}} \zeta_{\mathrm{N}}\left(x_{3}, x_{4}\right)+\frac{1}{2} \widetilde{\theta}^{\mathrm{T}} \mathbf{Q} \Gamma \tilde{\boldsymbol{\theta}} .
\end{aligned}
$$

Under assumption (26), we can obtain that

$$
\dot{\tilde{\boldsymbol{\theta}}}=\dot{\boldsymbol{\theta}}-\dot{\widehat{\boldsymbol{\theta}}}=-\dot{\hat{\boldsymbol{\theta}}}=-x_{1} \mathbf{Q}^{-1} \boldsymbol{\omega} .
$$

Differentiate $V_{2}$ along the trajectory given by (25), (28), and (30), and then we have

$$
\begin{aligned}
\dot{V}_{2}(\mathbf{x}, \widetilde{\boldsymbol{\theta}})= & -\frac{\beta\left(x_{1}-x_{2}\right)^{2}}{\left(n_{\mathrm{r} 0}+x_{1}\right)\left(n_{\mathrm{r} 0}+x_{2}\right)}-k_{\mathrm{n}} x_{1}^{2} \\
& -\frac{k_{\mathrm{f}}^{\prime} \Omega}{(1+\Omega / M) P_{0}}\left[x_{3}^{2}+\left(1+\frac{2 M}{\Omega}+\frac{2 \mu_{\mathrm{c}}}{\mu_{\mathrm{f}}}\right) x_{4}^{2}\right],
\end{aligned}
$$

from which we can see that adaptive virtual control (28) provides globally asymptotic closed-loop stability for subsystem (25), if $k_{\mathrm{f}}^{\prime}$ is positive. This completes the proof of this theorem.

Remark 3. From adaptive law (29), we have

$$
\widehat{\boldsymbol{\theta}}=\mathbf{Q}^{-1} \int_{t_{0}}^{t} x_{1} \omega \mathrm{d} \tau,
$$

where $t$ and $t_{0}$ are, respectively, the current and initial time. Substitute (49) to control law (28), and it is clear that

$$
\xi_{\mathrm{r}}=-k_{\mathrm{n}} x_{1}-k_{\mathrm{f}} x_{3}-k_{\mathrm{c}} x_{4}-\omega^{\mathrm{T}} \mathbf{\Gamma} \mathbf{Q}^{-1} \int_{t_{0}}^{t} x_{1} \omega \mathrm{d} \tau .
$$

Based upon (50), this nonlinear adaptive controller takes the form as a PI control, and the integration term here is just introduced to compensate the uncertainty.

Remark 4. From (46), positive scalars $q_{i}(i=1, \ldots, 4)$ is the weighting factors of $\tilde{\theta}_{i}$ in $V_{2}$. Here, $q_{i}$ is larger and the influence of $V_{1}$ to $V_{2}$ is smaller, which may lead to worse control performance.
Nonlinear adaptive stabilizer (28) determines the referenced value of $\xi$, that is, the reactivity that should be induced by the control rods. In the following part of this subsection, this stabilizer is used to design control input $u$ for entire system (6). Design and performance analysis of control input $u$ is summarized as Theorem 8 , which is the second main result in this paper.

Theorem 5. Consider control input of entire system (6)

$$
u=-k_{\xi 1} x_{1}-k_{\xi 2} e_{\xi}+\dot{\xi}_{\mathrm{r}},
$$

where both scalars $k_{\xi 1}$ and $k_{\xi_{2}}$ are positive, $\xi_{\mathrm{r}}$ is just the virtual control given in Theorem 2, and

$$
e_{\xi}=\xi-\xi_{\mathrm{r}}
$$

Then, control input (51) can guarantee the globally asymptotic closed-loop stability.

Proof. Choose the Lyapunov function for the closed-loop system formed by system (6) and control input (51) as

$$
\begin{aligned}
V_{3}\left(\mathbf{x}, \widetilde{\boldsymbol{\theta}}, e_{\xi}\right)= & V_{2}(\mathbf{x}, \widetilde{\boldsymbol{\theta}})+\frac{1}{2 k_{\xi 1}} e_{\xi}^{2}=n_{\mathrm{r} 0} \zeta_{\mathrm{T}}\left(x_{1}, x_{2}\right) \\
& +\frac{k_{\mathrm{f}}^{\prime}}{(1+\Omega / M) P_{0}} \zeta_{\mathrm{N}}\left(x_{3}, x_{4}\right) \\
& +\frac{1}{2} \widetilde{\boldsymbol{\theta}}^{\mathrm{T}} \mathbf{Q} \Gamma \tilde{\boldsymbol{\theta}}+\frac{1}{2 k_{\xi 1}} e_{\xi}^{2} .
\end{aligned}
$$

Differentiate $V_{3}$ along the trajectory given by system (6), control input (51), virtual control (28), and adaptive law (30), and we can derive that

$$
\begin{aligned}
\dot{V}_{3}= & -\frac{\beta\left(x_{1}-x_{2}\right)^{2}}{\left(n_{\mathrm{r} 0}+x_{1}\right)\left(n_{\mathrm{r} 0}+x_{2}\right)}-k_{\mathrm{n}} x_{1}^{2} \\
& -\frac{k_{\mathrm{f}}^{\prime} \Omega}{(1+\Omega / M) P_{0}}\left[x_{3}^{2}+\left(1+\frac{2 M}{\Omega}+\frac{2 \mu_{\mathrm{c}}}{\mu_{\mathrm{f}}}\right) x_{4}^{2}\right] \\
& +x_{1} e_{\xi}+\frac{e_{\xi}}{k_{\xi 1}}\left(u-\dot{\xi}_{\mathrm{r}}\right) \\
= & -\frac{\beta\left(x_{1}-x_{2}\right)^{2}}{\left(n_{\mathrm{r} 0}+x_{1}\right)\left(n_{\mathrm{r} 0}+x_{2}\right)}-k_{\mathrm{n}} x_{1}^{2} \\
& -\frac{k_{\mathrm{f}}^{\prime} \Omega}{(1+\Omega / M) P_{0}}\left[x_{3}^{2}+\left(1+\frac{2 M}{\Omega}+\frac{2 \mu_{\mathrm{c}}}{\mu_{\mathrm{f}}}\right) x_{4}^{2}\right] \\
& -\frac{k_{\xi 2}}{k_{\xi 1}} e_{\xi}^{2} .
\end{aligned}
$$

From (54), state vector of entire system (6) converges to the origin asymptotically, which completes the proof of Theorem 5.

3.2. State-Observer Design. Although nonlinear adaptive control (51) guarantees the globally asymptotical convergence 
of the reactor state, the precondition is that state-vector $\mathbf{x}$ can be measured directly. Actually, $x_{2}$ and $x_{3}$, that is, variations of the relative concentration of delayed neutron precursor and the average fuel temperature, cannot be measured directly. Therefore, it is necessary to design a state-observer. Theorem 6 gives a bounded state-observer of system (6), which is the third main result.

Theorem 6. Suppose (26) is well satisfied, and moreover assume that

$$
c_{\mathrm{r}}=c_{\mathrm{r} 0}+x_{2}=n_{\mathrm{r} 0}+x_{2} \leq C .
$$

Consider the state-observer of system (6) that takes the form as

$$
\begin{gathered}
\dot{\widehat{\mathbf{x}}}=\mathbf{f}(\widehat{\mathbf{x}})+\mathbf{g}(\widehat{\mathbf{x}}) \hat{\xi}+\mathbf{K}_{\mathrm{o}} \mathbf{e}_{\mathrm{o}}+\mathbf{H}_{\mathrm{o}} \boldsymbol{\vartheta}_{\mathrm{o}}, \\
\dot{\vec{\xi}}=u+k_{\mathrm{o} \xi}\left(n_{\mathrm{r} 0}+x_{1}\right) e_{1},
\end{gathered}
$$

where $\widehat{\mathbf{x}}=\left[\begin{array}{llll}\widehat{x}_{1} & \widehat{x}_{2} & \widehat{x}_{3} & \widehat{x}_{4}\end{array}\right]^{\mathrm{T}} \in R^{4}$ is the state-observation, $\hat{\xi}$ is the observation of $\xi$, and vector-valued functions $\mathbf{f}$ and $\mathbf{g}$ are determined by (11) and (12), respectively,

$$
\begin{aligned}
& \mathbf{e}_{\mathrm{o}}=\left[\begin{array}{ll}
e_{1} & e_{4}
\end{array}\right]^{\mathrm{T}}=\left[\begin{array}{ll}
x_{1}-\widehat{x}_{1} & x_{4}-\widehat{x}_{4}
\end{array}\right]^{\mathrm{T}}, \\
& \boldsymbol{\vartheta}_{\mathrm{o}}=\left[\begin{array}{ll}
\vartheta_{1} & \vartheta_{4}
\end{array}\right]^{\mathrm{T}}, \\
& \mathbf{K}_{\mathrm{o}}=\left[\begin{array}{cccc}
k_{\mathrm{on}}+\frac{\alpha_{\mathrm{f}} \widehat{x}_{3}+\alpha_{\mathrm{c}} \widehat{x}_{4}+\widehat{\xi}}{\Lambda} & 2 \lambda & -\frac{P_{0}}{\mu_{\mathrm{f}}}\left[k_{\mathrm{of}}\left(n_{\mathrm{r} 0}+x_{1}\right)-1\right] & -\frac{\alpha_{\mathrm{c}} P_{0}}{\alpha_{\mathrm{f}} \mu_{\mathrm{f}}} k_{\mathrm{of}}\left(n_{\mathrm{r} 0}+x_{1}\right) \\
0 & 0 & \frac{2 \Omega}{\mu_{\mathrm{f}}} & k_{\mathrm{oc}}
\end{array}\right]^{\mathrm{T}}, \\
& \mathbf{H}_{\mathrm{o}}=\left[\begin{array}{cccc}
n_{\mathrm{r} 0}+x_{1} & 0 & 0 & 0 \\
0 & 0 & 0 & x_{1}
\end{array}\right]^{\mathrm{T}}, \\
& \dot{\boldsymbol{\vartheta}}_{\mathrm{o}}=\boldsymbol{\varphi}\left(x_{1}, \mathbf{e}_{\mathrm{o}}\right), \\
& \boldsymbol{\varphi}\left(\mathbf{e}_{\mathrm{o}}, x_{1}\right)=\left[\left(n_{\mathrm{r} 0}+x_{1}\right) e_{1} x_{1} e_{4}\right]^{\mathrm{T}},
\end{aligned}
$$

and positive scalars $k_{\mathrm{on}}, k_{\mathrm{of}}$, and $k_{\mathrm{oc}}$ are all observer gains. Observer (56) provides state-observation with bounded observing error that can be satisfactory small if both observer gains $k_{\mathrm{oN}}$ and $k_{\mathrm{oT}}$ are high enough.

Proof. Define the observer error vector as

$$
\mathbf{e}=\left[\begin{array}{lllll}
e_{1} & e_{2} & e_{3} & e_{4} & e_{5}
\end{array}\right]=\left[\begin{array}{lll}
\mathbf{x}^{\mathrm{T}}-\widehat{\mathbf{x}}^{\mathrm{T}} & \xi-\hat{\xi}
\end{array}\right]^{\mathrm{T}} .
$$

From (6) and (56), it is clear that the observation error $\mathbf{e}$ satisfies

$$
\begin{aligned}
\Lambda \dot{e}_{1}= & -\beta\left(e_{1}-e_{2}\right)+\left(n_{\mathrm{r} 0}+x_{1}\right)\left(\alpha_{\mathrm{f}} e_{3}+\alpha_{\mathrm{c}} e_{4}+e_{5}\right) \\
& +\Lambda\left(n_{\mathrm{r} 0}+x_{1}\right) \widetilde{\vartheta}_{1}-\Lambda k_{\mathrm{on}} e_{1}, \\
\dot{e}_{2}= & \lambda\left(e_{1}-e_{2}\right)-2 \lambda e_{1}+x_{1}\left(n_{\mathrm{r} 0}+x_{2}\right) \theta_{2}, \\
\mu_{\mathrm{f}} \dot{e}_{3}= & P_{0} e_{1}-\Omega\left(e_{3}-e_{4}\right) \\
& +P_{0}\left[k_{\mathrm{of}}\left(n_{\mathrm{r} 0}+x_{1}\right)-1\right] e_{1}-2 \Omega e_{4}+\mu_{\mathrm{f}} x_{1} \theta_{3},
\end{aligned}
$$

$$
\begin{gathered}
\mu_{\mathrm{c}} \dot{e}_{4}=\Omega\left(e_{3}-e_{4}\right)-2 M e_{4}+\mu_{\mathrm{c}} x_{1} \widetilde{\vartheta}_{4} \\
-\mu_{\mathrm{c}} k_{\mathrm{oc}} e_{4}+\frac{\alpha_{\mathrm{c}}}{\alpha_{\mathrm{f}}} P_{0} k_{\mathrm{of}}\left(n_{\mathrm{r} 0}+x_{1}\right) e_{1}, \\
\dot{e}_{5}=-k_{\mathrm{o} \xi}\left(n_{\mathrm{r} 0}+x_{1}\right) e_{1},
\end{gathered}
$$

where

$$
\widetilde{\vartheta}_{k}=\theta_{k}-\vartheta_{k}, \quad k=1,4 .
$$

Choose the Lyapunov function for observer error dynamics (64) as

$$
\begin{aligned}
V_{\mathrm{e} 1}(\mathbf{e})= & \frac{\Lambda}{2} e_{1}^{2}+\frac{\beta}{2 \lambda} e_{2}^{2} \\
& +\frac{\left|\alpha_{\mathrm{f}}\right|}{2 P_{0} k_{\mathrm{of}}}\left(\mu_{\mathrm{f}} e_{3}^{2}+\mu_{\mathrm{c}} e_{4}^{2}\right)+\frac{1}{2 k_{\mathrm{o}}} e_{5}^{2},
\end{aligned}
$$


and by differentiating $V_{\mathrm{e} 1}$ along the trajectory given by (64), we can derive that

$$
\begin{aligned}
\dot{V}_{\mathrm{e} 1}= & -\beta\left(e_{1}^{2}+e_{2}^{2}\right)-\Lambda k_{\mathrm{on}} e_{1}^{2} \\
& +\left(n_{\mathrm{r} 0}+x_{1}\right)\left(\alpha_{\mathrm{f}} e_{1} e_{3}+\alpha_{\mathrm{c}} e_{1} e_{4}+e_{1} e_{5}\right) \\
& +\Lambda\left(n_{\mathrm{r} 0}+x_{1}\right) e_{1} \widetilde{\vartheta}_{1}+\frac{\beta}{\lambda}\left(n_{\mathrm{r} 0}+x_{2}\right) x_{1} e_{2} \theta_{2}+\frac{\left|\alpha_{\mathrm{f}}\right|}{P_{0} k_{\mathrm{of}}} \\
& \times\left[-\Omega\left(e_{3}^{2}+e_{4}^{2}\right)-2 M e_{4}^{2}-\mu_{\mathrm{d}} e_{4}^{2}+k_{\mathrm{of}} P_{0}\left(n_{\mathrm{r} 0}+x_{1}\right) e_{1}\right. \\
& \left.\times\left(e_{3}+\frac{\alpha_{\mathrm{c}}}{\alpha_{\mathrm{f}}} e_{4}\right)+\mu_{\mathrm{f}} x_{1} e_{3} \theta_{3}+\mu_{\mathrm{c}} x_{1} e_{4} \widetilde{\vartheta}_{4}\right] \\
& -\left(n_{\mathrm{r} 0}+x_{1}\right) e_{1} e_{5} \\
= & -\beta\left(e_{1}^{2}+e_{2}^{2}\right)-\frac{\left|\alpha_{\mathrm{f}}\right| \Omega}{P_{0} k_{\mathrm{of}}}\left[e_{3}^{2}+\left(1+\frac{2 M}{\Omega}\right) e_{4}^{2}\right] \\
& +\frac{\left|\alpha_{\mathrm{f}}\right| x_{1}}{P_{0} k_{\mathrm{of}}}\left(\mu_{\mathrm{f}} e_{3} \theta_{3}+\mu_{\mathrm{c}} e_{4} \widetilde{\vartheta}_{4}\right) . \\
& -\Lambda k_{\mathrm{on}} e_{1}^{2}-\frac{\left|\alpha_{\mathrm{f}}\right| \mu_{\mathrm{c}} k_{\mathrm{oc}}}{P_{0} k_{\mathrm{of}}} e_{4}^{2}+\Lambda\left(n_{\mathrm{r} 0}+x_{1}\right) e_{1} \widetilde{\vartheta}_{1} \\
& \beta x_{2} \theta_{2} \\
& \\
& \\
&
\end{aligned}
$$

Then, define the Lyapunov function of both observer (56) and parameter adaptive law (61) as

$$
V_{\mathrm{e}}\left(\mathbf{e}, \widetilde{\boldsymbol{\vartheta}}_{\mathrm{o}}\right)=V_{\mathrm{e} 1}(\mathbf{e})+\frac{1}{2} \widetilde{\boldsymbol{\vartheta}}_{\mathrm{o}}^{\mathrm{T}} \boldsymbol{\Pi} \widetilde{\boldsymbol{\vartheta}}_{\mathrm{o}}
$$

where

$$
\widetilde{\boldsymbol{\vartheta}}_{\mathrm{o}}=\left[\begin{array}{ll}
\theta_{1}-\vartheta_{1} & \theta_{4}-\vartheta_{4}
\end{array}\right]^{\mathrm{T}}
$$

and $\Pi$ is a diagonal positive-definite matrix given by

$$
\Pi=\operatorname{diag}\left(\left[\Lambda \frac{\left|\alpha_{\mathrm{c}}\right| \mu_{\mathrm{c}}}{P_{0} k_{\mathrm{of}}}\right]\right)
$$

Moreover, since we have assumed that (26), it is clear that

$$
\dot{\tilde{\boldsymbol{\vartheta}}}_{\mathrm{o}}=-\dot{\boldsymbol{\vartheta}}_{\mathrm{o}}=-\boldsymbol{\varphi}\left(x_{1}, \mathbf{e}_{\mathrm{o}}\right) \text {. }
$$

Differentiate $V_{\mathrm{e}}$ along the trajectory given by observer (56) and adaptive law (71),

$$
\begin{aligned}
& \dot{V}_{\mathrm{e}}=\dot{V}_{\mathrm{e} 1}+\tilde{\boldsymbol{\vartheta}}_{\mathrm{o}}^{\mathrm{T}} \boldsymbol{\Pi} \dot{\widetilde{\vartheta}}_{\mathrm{o}}=-\beta\left(e_{1}^{2}+e_{2}^{2}\right) \\
& -\frac{\left|\alpha_{\mathrm{f}}\right| \Omega}{P_{0} k_{\mathrm{of}}}\left[e_{3}^{2}+\left(1+\frac{2 M}{\Omega}\right) e_{4}^{2}\right]-\Lambda k_{\mathrm{on}} e_{1}^{2} \\
& -\frac{\left|\alpha_{\mathrm{f}}\right| \mu_{\mathrm{c}} k_{\mathrm{oc}}}{P_{0} k_{\mathrm{of}}} e_{4}^{2}+\Lambda\left(n_{\mathrm{r} 0}+x_{1}\right) e_{1} \widetilde{\vartheta}_{1} \\
& +\frac{\beta}{\lambda}\left(n_{\mathrm{r} 0}+x_{2}\right) x_{1} e_{2} \theta_{2} \\
& +\frac{\left|\alpha_{\mathrm{f}}\right| x_{1}}{P_{0} k_{\mathrm{of}}}\left(\mu_{\mathrm{f}} e_{3} \theta_{3}+\mu_{\mathrm{c}} e_{4} \widetilde{\vartheta}_{4}\right)-\widetilde{\boldsymbol{\vartheta}}_{\mathrm{o}}^{\mathrm{T}} \boldsymbol{\Pi} \boldsymbol{\varphi}\left(\mathbf{e}_{\mathrm{o}}, x_{1}\right) \\
& =-\beta\left(e_{1}^{2}+e_{2}^{2}\right)-\frac{\left|\alpha_{\mathrm{f}}\right| \Omega}{P_{0} k_{\mathrm{of}}}\left[\frac{e_{3}^{2}}{2}+\left(1+\frac{2 M}{\Omega}\right) e_{4}^{2}\right] \\
& -\Lambda k_{\mathrm{on}} e_{1}^{2}-\frac{\left|\alpha_{\mathrm{f}}\right| \mu_{\mathrm{c}} k_{\mathrm{oc}}}{P_{0} k_{\mathrm{of}}} e_{4}^{2}+\frac{\beta}{\lambda}\left(n_{\mathrm{r} 0}+x_{2}\right) x_{1} e_{2} \theta_{2} \\
& +\frac{\left|\alpha_{\mathrm{f}}\right| \mu_{\mathrm{f}}}{P_{0} k_{\mathrm{of}}} x_{1} e_{3} \theta_{3} \\
& \leq-\beta\left(e_{1}^{2}+\frac{e_{2}^{2}}{2}\right) \\
& -\frac{\left|\alpha_{\mathrm{f}}\right| \Omega}{P_{0} k_{\mathrm{of}}}\left[\frac{e_{3}^{2}}{2}+\left(1+\frac{2 M}{\Omega}\right) e_{4}^{2}\right] \\
& -\frac{\beta}{2}\left[e_{2}-\frac{1}{\lambda}\left(n_{\mathrm{r} 0}+x_{1}\right) x_{1} \theta_{2}\right]^{2} \\
& -\frac{\left|\alpha_{\mathrm{f}}\right| \Omega}{2 P_{0} k_{\mathrm{of}}}\left(e_{3}-\frac{\mu_{\mathrm{f}}}{\Omega} x_{1} \theta_{3}\right)^{2}+\frac{\beta}{2 \lambda^{2}}\left(n_{\mathrm{r} 0}+x_{2}\right)^{2} x_{1}^{2} \theta_{2}^{2} \\
& +\frac{\left|\alpha_{\mathrm{f}}\right| \mu_{\mathrm{f}}^{2}}{2 \Omega P_{0} k_{\mathrm{of}}} x_{1}^{2} \theta_{3}^{2}-\left(\Lambda k_{\mathrm{on}} e_{1}^{2}+\frac{\left|\alpha_{\mathrm{f}}\right| \mu_{\mathrm{c}} k_{\mathrm{oc}}}{P_{0} k_{\mathrm{of}}} e_{4}^{2}\right) \text {. }
\end{aligned}
$$

Based on both assumptions (26) and (55), it is clear from (72) that

$$
\dot{V}_{\mathrm{e}} \leq-\mathrm{e}^{\mathrm{T}} \mathrm{Me}+C_{\mathrm{M}} x_{1}^{2}-\left(\Lambda k_{\mathrm{on}} e_{1}^{2}+\frac{\left|\alpha_{\mathrm{f}}\right| \mu_{\mathrm{c}} k_{\mathrm{oc}}}{P_{0} k_{\mathrm{of}}} e_{4}^{2}\right),
$$

where

$$
\begin{gathered}
\mathbf{M}=\operatorname{diag}\left(\left[\beta \frac{\beta}{2} \frac{\left|\alpha_{\mathrm{f}}\right| \Omega}{2 P_{0} k_{\mathrm{of}}} \frac{\left|\alpha_{\mathrm{f}}\right| \Omega}{P_{0} k_{\mathrm{of}}}\left(1+\frac{2 M}{\Omega}\right) 0\right]\right), \\
C_{\mathrm{M}}=\frac{\beta}{2 \lambda^{2}} C^{2} M_{2}^{2}+\frac{\left|\alpha_{\mathrm{f}}\right| \mu_{\mathrm{f}}^{2}}{2 \Omega P_{0} k_{\mathrm{of}}} M_{3}^{2} .
\end{gathered}
$$

From inequality (73), the observation error e enters to the ball given by

$$
B_{\mathrm{e}}=\left\{\mathbf{e} \mid \mathbf{e}^{\mathrm{T}} \mathbf{M e} \leq C_{\mathrm{M}} x_{1}^{2}-\left(\Lambda k_{\mathrm{on}} e_{1}^{2}+\frac{\left|\alpha_{\mathrm{f}}\right| \mu_{\mathrm{c}} k_{\mathrm{oc}}}{P_{0} k_{\mathrm{of}}} e_{4}^{2}\right)\right\}
$$


from which we can see that if both $k_{\mathrm{on}}$ and $k_{\mathrm{oc}}$ are larger, then the observation error is nearer to the origin. This completes the proof of Theorem 6 .

Remark 7. From inequality (73), if

$$
\lim _{t \rightarrow \infty} x_{1}(t)=0
$$

then the observation error vector enters to the set

$$
S_{\mathrm{e}}=\left\{\mathbf{e} \mid e_{1}=e_{2}=e_{3}=e_{4} \equiv 0\right\} .
$$

Further, from the last equation of observation error dynamics (64), $e_{5}$ is a bounded constant.

3.3. Stability of Closed-Loop Stability. From Theorems 2, 5, and 6 , the nonlinear adaptive dynamic output-feedback power-level control strategy for the nuclear heating reactor can be written as

$$
\begin{gathered}
u=-k_{\xi 1} x_{1}-k_{\xi 2} e_{\xi}+\dot{\vec{\xi}}_{\mathrm{r}}, \\
\widehat{\xi}_{\mathrm{r}}=-k_{\mathrm{n}} x_{1}-k_{\mathrm{f}} \widehat{x}_{3}-k_{\mathrm{c}} x_{4}-\widehat{\boldsymbol{\theta}}^{\mathrm{T}} \boldsymbol{\Gamma} \widehat{\boldsymbol{\omega}}, \\
\dot{\hat{\boldsymbol{\theta}}}=x_{1} \mathbf{Q}^{-1} \widehat{\boldsymbol{\omega}}, \\
\dot{\widehat{\mathbf{x}}}=\mathbf{f}(\widehat{\mathbf{x}})+\mathbf{g}(\widehat{\mathbf{x}}) \widehat{\xi}+\mathbf{K}_{\mathrm{o}} \mathbf{e}_{\mathrm{o}}+\mathbf{H}_{\mathrm{o}} \boldsymbol{\vartheta}_{\mathrm{o}}, \\
\dot{\vec{\xi}}=u+k_{\mathrm{o} \xi}\left(n_{\mathrm{r} 0}+x_{1}\right) e_{1}, \\
\dot{\boldsymbol{\vartheta}}_{\mathrm{o}}=\boldsymbol{\varphi}\left(x_{1}, \mathbf{e}_{\mathrm{o}}\right),
\end{gathered}
$$

where

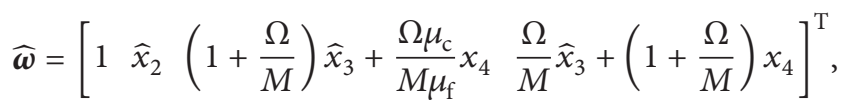

scalar $k_{\mathrm{c}}$ is given by (31), matrices $\boldsymbol{\Gamma}, \mathbf{Q}, \mathbf{K}_{\mathrm{o}}$, and $\mathbf{H}_{\mathrm{o}}$ are, respectively, given by (33), (35), (59), and (60), and vectorvalued functions $\mathbf{f}, \mathbf{g}$, and $\boldsymbol{\varphi}$ are determined by (11), (12), and (62), respectively.

In this section, we will study whether nonlinear adaptive control law (79) can provide the globally asymptotic stability of the reactor. The result for stability analysis of the closedloop system formed by system (6) and control strategy (78) is summarized as Theorem 8 which is the fourth main result of this paper.

Theorem 8. Suppose that both (26) and (55) are well satisfied. Consider nonlinear adaptive dynamic output-feedback powerlevel control (78). If

$$
\begin{aligned}
\bar{k}_{\mathrm{n}}=k_{\mathrm{n}}-\frac{\beta}{2 \lambda^{2}}(1+C)^{2} M_{2}^{2}-\frac{k_{\mathrm{f}}^{2} k_{\mathrm{of}} P_{0}}{2\left|\alpha_{\mathrm{f}}\right| \Omega} \\
\times\left\{1+\frac{\mu_{\mathrm{f}}}{P_{0}}\left(1-\frac{\alpha_{\mathrm{f}}}{k_{\mathrm{f}}}\right)\left[1+k_{\mathrm{of}}^{-1}\left(1-\frac{k_{\mathrm{f}}}{\alpha_{\mathrm{f}}}\right)^{-1}\right.\right. \\
\left.\left.+\frac{\Omega \mu_{f}}{(M+\Omega) \mu_{\mathrm{c}}}\right]\right\}^{2} M_{3}^{2}
\end{aligned}
$$

is a positive scalar, then the closed-loop system constituted by system (6) and control strategy (78) is globally asymptotically stable.

Proof. Similar to Theorems 2, 5, and 6, Theorem 8 will also be proved by Lyapunov direct method. Select the Lyapunov function for the entire closed-loop system formed by (6) and (78) as

$$
V_{4}\left(\mathbf{x}, \widetilde{\boldsymbol{\theta}}, e_{\xi}, \mathbf{e}, \widetilde{\boldsymbol{\vartheta}}_{\mathrm{o}}\right)=V_{3}\left(\mathbf{x}, \widetilde{\boldsymbol{\theta}}, e_{\xi}\right)+V_{\mathrm{e}}\left(\mathbf{e}, \widetilde{\boldsymbol{\vartheta}}_{\mathrm{o}}\right)
$$

Differentiate $V_{4}$ along the trajectory determined by both system model (6) and control (78),

$$
\begin{aligned}
& \dot{V}_{4}=\dot{V}_{3}\left(\mathbf{x}, \widetilde{\boldsymbol{\theta}}, e_{\xi}\right)+\dot{V}_{\mathrm{e}}\left(\mathbf{e}, \widetilde{\boldsymbol{\vartheta}}_{\mathrm{o}}\right) \\
& =-k_{\mathrm{n}} x_{1}^{2}-\frac{\beta\left(x_{1}-x_{2}\right)^{2}}{\left(n_{\mathrm{r} 0}+x_{1}\right)\left(n_{\mathrm{r} 0}+x_{2}\right)} \\
& -\frac{k_{\mathrm{f}}^{\prime} \Omega}{(1+\Omega / M) P_{0}}\left[x_{3}^{2}+\left(1+\frac{2 M}{\Omega}+\frac{2 \mu_{\mathrm{c}}}{\mu_{\mathrm{f}}}\right) x_{4}^{2}\right] \\
& +\tilde{\boldsymbol{\theta}}^{\mathrm{T}} \boldsymbol{\Gamma}\left(\dot{\tilde{\boldsymbol{\theta}}}+x_{1} \widehat{\boldsymbol{\omega}}\right)+\frac{\beta}{\lambda} \theta_{2} e_{2} x_{1} \\
& +\left[k_{\mathrm{f}}+\frac{k_{\mathrm{f}}^{\prime} \mu_{\mathrm{f}}}{(1+\Omega / M) P_{0}}\left(1+\frac{\Omega}{M}+\frac{\Omega \mu_{\mathrm{c}}}{M \mu_{\mathrm{f}}}\right) \theta_{3}\right] e_{3} x_{1} \\
& -\frac{k_{\xi 2}}{k_{\xi 1}} e_{\xi}^{2}-\left(\beta+\Lambda k_{\text {on }}\right) e_{1}^{2}-\beta e_{2}^{2} \\
& -\frac{\left|\alpha_{\mathrm{f}}\right| \Omega}{k_{\mathrm{of}} P_{0}}\left[e_{3}^{2}+\left(1+\frac{2 M+\mu_{\mathrm{c}} k_{\mathrm{oc}}}{\Omega}\right) e_{4}^{2}\right] \\
& +\frac{\beta}{\lambda}\left(n_{\mathrm{r} 0}+x_{2}\right) \theta_{2} e_{2} x_{1}+\frac{\left|\alpha_{\mathrm{f}}\right| \mu_{\mathrm{f}}}{k_{\mathrm{of}} P_{0}} \theta_{3} e_{3} x_{1} \\
& =-\frac{\beta\left(x_{1}-x_{2}\right)^{2}}{\left(n_{\mathrm{r} 0}+x_{1}\right)\left(n_{\mathrm{r} 0}+x_{2}\right)}-\frac{k_{\mathrm{f}}^{\prime} \Omega}{(1+\Omega / M) P_{0}} \\
& \times\left[x_{3}^{2}+\left(1+\frac{2 M}{\Omega}+\frac{2 \mu_{\mathrm{c}}}{\mu_{\mathrm{f}}}\right) x_{4}^{2}\right]-\frac{k_{\xi 2}}{k_{\xi 1}} e_{\xi}^{2} \\
& -\left(\beta+\Lambda k_{\text {on }}\right) e_{1}^{2}-\frac{\beta}{2} e_{2}^{2} \\
& -\frac{\left|\alpha_{\mathrm{f}}\right| \Omega}{k_{\mathrm{of}} P_{0}}\left[\frac{e_{3}^{2}}{2}+\left(1+\frac{2 M+\mu_{\mathrm{c}} k_{\mathrm{oc}}}{\Omega}\right) e_{4}^{2}\right] \\
& -\frac{\beta}{2}\left(e_{2}-\frac{1+n_{\mathrm{r} 0}+x_{2}}{\lambda} \theta_{2} x_{1}\right)^{2}
\end{aligned}
$$




$$
\begin{aligned}
& -\frac{\left|\alpha_{\mathrm{f}}\right| \Omega}{2 k_{\mathrm{of}} P_{0}}\left\{e_{3}-k_{\mathrm{of}}\left[\frac{k_{\mathrm{f}} P_{0}}{\left|\alpha_{\mathrm{f}}\right| \Omega}+\frac{\mu_{\mathrm{f}}}{\Omega}\left(1-\frac{k_{\mathrm{f}}}{\alpha_{\mathrm{f}}}\right)\right.\right. \\
& \times\left(1+k_{\text {of }}^{-1}\left(1-\frac{k_{\mathrm{f}}}{\alpha_{\mathrm{f}}}\right)^{-1}\right. \\
& \left.\left.+\frac{\Omega \mu_{\mathrm{c}}}{(M+\Omega) \mu_{\mathrm{f}}}\right)\right] \\
& \left.\times \theta_{3} x_{1}\right\}^{2} \\
& -\left\{k_{\mathrm{n}}-\frac{\left(1+n_{\mathrm{r} 0}+x_{2}\right)^{2}}{2 \lambda^{2}} \theta_{2}^{2}-\frac{k_{\mathrm{of}} P_{0}}{2\left|\alpha_{\mathrm{f}}\right| \Omega}\right. \\
& \times\left[k_{\mathrm{f}}+\frac{k_{\mathrm{f}}^{\prime} \mu_{\mathrm{f}}}{P_{0}}\left(1+k_{\mathrm{of}}^{-1}\left(1-\frac{k_{\mathrm{f}}}{\alpha_{\mathrm{f}}}\right)^{-1}\right.\right. \\
& \left.\left.\left.+\frac{\Omega \mu_{\mathrm{c}}}{(M+\Omega) \mu_{\mathrm{f}}}\right)\right]^{2} \times \theta_{3}^{2}\right\} x_{1}^{2} \\
& \leq-\bar{k}_{\mathrm{n}} x_{1}^{2}-\frac{\beta\left(x_{1}-x_{2}\right)^{2}}{\left(n_{\mathrm{r} 0}+x_{1}\right)\left(n_{\mathrm{r} 0}+x_{2}\right)} \\
& -\frac{k_{\mathrm{f}}^{\prime} \Omega}{(1+\Omega / M) P_{0}}\left[x_{3}^{2}+\left(1+\frac{2 M}{\Omega}+\frac{2 \mu_{\mathrm{c}}}{\mu_{\mathrm{f}}}\right) x_{4}^{2}\right] \\
& -\frac{k_{\xi 2}}{k_{\xi 1}} e_{\xi}^{2}-\left(\beta+\Lambda k_{\mathrm{on}}\right) e_{1}^{2}-\frac{\beta}{2} e_{2}^{2} \\
& -\frac{\left|\alpha_{\mathrm{f}}\right| \Omega}{k_{\mathrm{of}} P_{0}}\left[\frac{e_{3}^{2}}{2}+\left(1+\frac{2 M+\mu_{\mathrm{c}} k_{\mathrm{oc}}}{\Omega}\right) e_{4}^{2}\right],
\end{aligned}
$$

where $k_{\mathrm{f}}^{\prime}$ is defined in (34).

It is clear from inequality (82) that if $\bar{k}_{\mathrm{n}}$ is a positive scalar, then the state of the closed-loop system finally enters into the set

$$
\begin{aligned}
\Theta=\left\{\mathbf{x} \in \mathrm{R}^{4}, \mathbf{e} \in \mathrm{R}^{5}, e_{\xi} \in \mathrm{R} \mid\right. \\
\left.\quad x_{k}=0, e_{k}=0, e_{\xi}=0, k=1, \ldots, 4\right\},
\end{aligned}
$$

which means that the corresponding closed-loop system is globally asymptotically stable. This completes the proof of this theorem.

\section{Simulation Results with Discussion}

To verify the feasibility and the performance of nonlinear adaptive dynamic output-feedback power-level control strategy (78), it is applied to the power-level regulation of an NHR with the thermal power of $200 \mathrm{MW}$. Both the closed-loop stability and load following ability are illustrated by numerical simulation results.

4.1. Description of the Numerical Simulation. The block diagram representation of the closed-loop constructed by the
NHR model and the newly built nonlinear adaptive powerlevel control law is given in Figure 1 , where $n_{\mathrm{r}, \mathrm{m}}$ and $n_{\mathrm{r}, \mathrm{r}}$ are the relative neutron density given by the measurement and load signal, respectively, and $T_{\text {cav, } m}$ and $T_{\text {cav,r } r}$ are the average coolant temperature determined by measurement and load signal, respectively. Here, the simulation model of the NHR, which was developed by INET, contains point kinetics model with six delayed neutron groups (7th order), 2nd-order heat exchange dynamics of the reactor core, 2nd-order dynamics of primary heat exchanger, 5th-order dynamics of a U-tube steam generator (UTSG) with a water-level controller and bypass system, 2nd-order dynamics of the pump of UTSG, and 6th-order dynamics of other heat transmission pipe or volume cells [30]. The water-level control of the UTSG adopts that one presented in [31].

4.2. Simulation Results. In this simulation, choose $\mathbf{Q}=q \mathbf{I}$ where $q$ is a given positive scalar. Set $k_{\mathrm{n}}=10.0, k_{\mathrm{f}}=0.1$, $k_{\xi 1}=k_{\xi 2}=0.1, k_{\text {on }}=1000, k_{\text {oc }}=100, k_{\text {of }}=0.01$, and $k_{\mathrm{o} \xi}=0.5$. Here, the maximal control rod speed is $0.5 \mathrm{~cm} / \mathrm{s}$.

Two case studies are done to show the control performance.

Case A (large load lift). Load signal changes linearly from $20 \%$ to $100 \%$ in 60 s:

(1) load lift with varying $k_{\mathrm{f}}$ and constant $q$;

(2) load lift with constant $k_{\mathrm{f}}$ and varying $q$.

Case B (load rejection). Load signal steps down from $100 \%$ to $20 \%$ immediately:

(1) load lift with varying $k_{\mathrm{f}}$ and constant $q$;

(2) load lift with constant $k_{\mathrm{f}}$ and varying $q$.

4.2.1. Large Load Lift. This verification represents a hard operation for the NHR. In this case, the power demand changes linearly from $20 \%$ to $100 \%$ in 60 seconds. The responses of the relative nuclear power, average fuel temperature, and outlet coolant temperature of the reactor core $T_{\text {cout }}$ and designed control rod speed with varying $k_{\mathrm{f}}$ and constant $q=500$ are all illustrated in Figure 3. The responses of these process variables corresponding to varying $q$ and constant $k_{\mathrm{f}}=0.005$ are all given in Figure 4 .

4.2.2. Load Rejection. This case also represents a stressed operation for the NHR. The load signal steps down from $100 \%$ to $20 \%$. The responses of the process variables with varying $k_{\mathrm{f}}$ and $q=500$ are shown in Figure 5. The results corresponding to varying $q$ and $k_{\mathrm{f}}=0.005$ are all given in Figure 6 .

4.3. Discussion. It is clear that the load increase leads $\delta n_{\mathrm{r}}$ to be negative and decreasing and drives the power-level controller to give a positive control rod speed signal. Withdrawing of the control rod leads to both increase of nuclear power and that of fuel temperature. The closed-loop system enters into a steady state if the reactivity given by the control rods cancels that caused by the temperature feedback effect. As we can see 


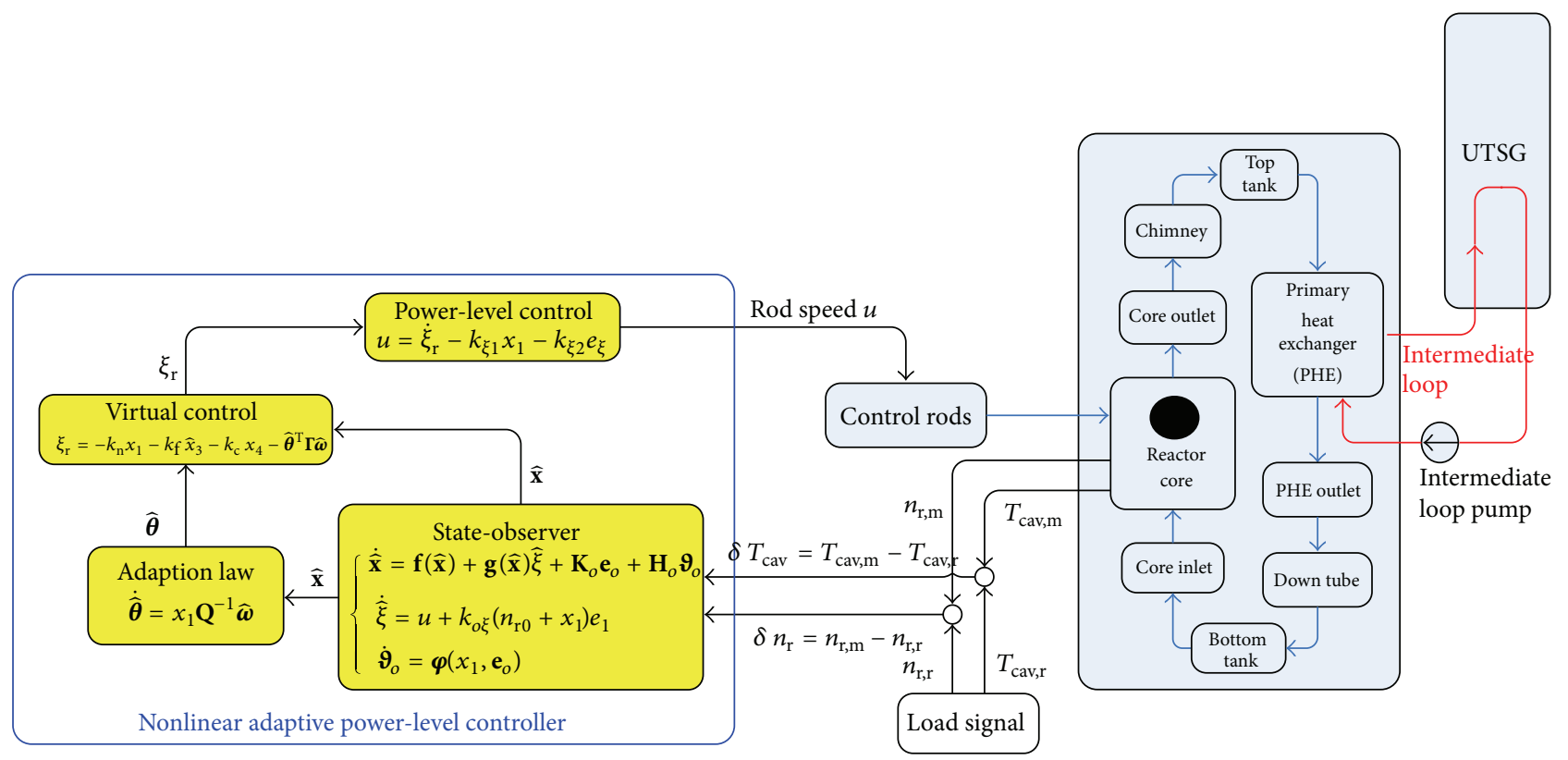

FIGURE 2: Block diagram representation of the closed-loop structure.

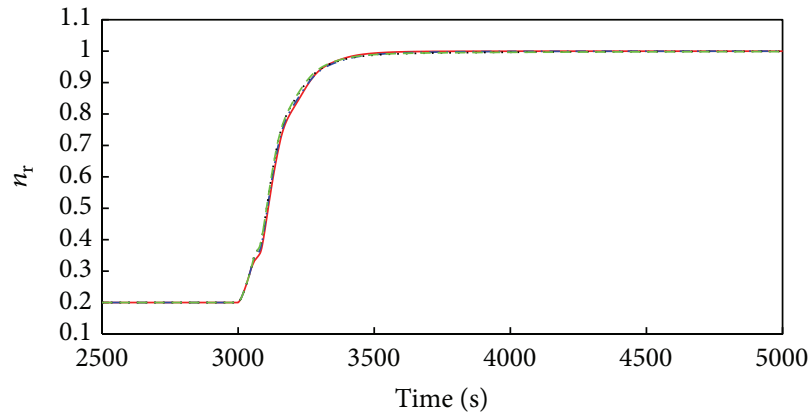

(a)

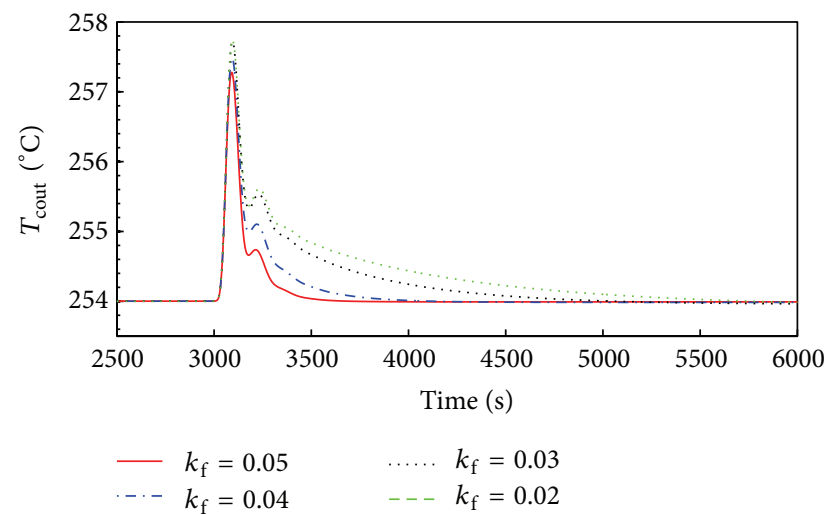

(c)

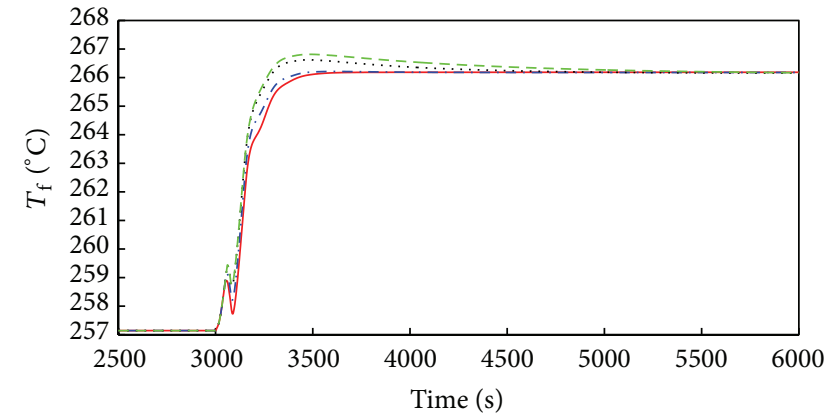

(b)

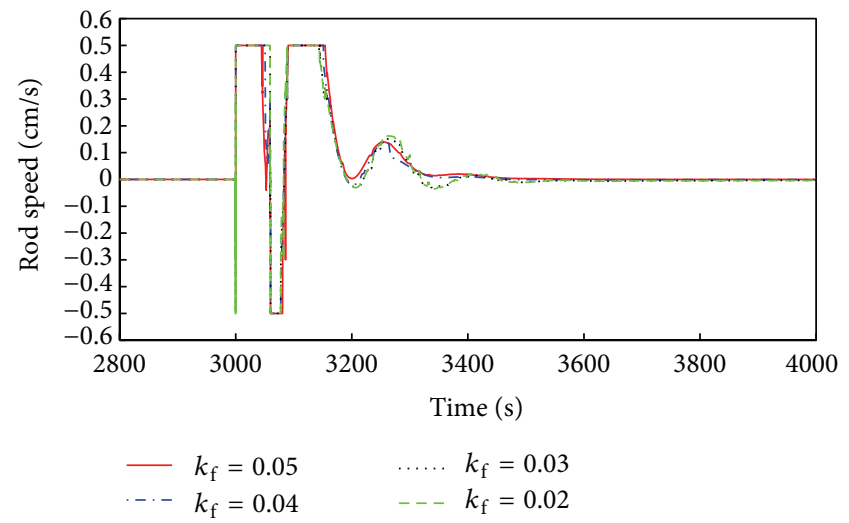

(d)

FIgURE 3: Simulation results in Case A(1).

from Figure 2, generation of the control rod speed signal is driven by the variations of relative nuclear power and average coolant temperature obtained from measurement. These two variation signals drive the state-observer to provide a convergent observation which then cause the power-level controller to generate the control rod speed signal.
From Figure 3, if $k_{\mathrm{f}}$ is larger, both transition time and overshoot of the fuel and outlet coolant temperatures are smaller. Actually, from (42) and (34), $k_{\mathrm{f}}$ is larger, the weight of shifted-ectropy $\zeta_{\mathrm{T}}$ in Lyapunov function $V_{1}$ is larger, which induces higher response quality of the fuel and coolant temperatures. From Figure 4, if $q$ is larger, then the dynamic 


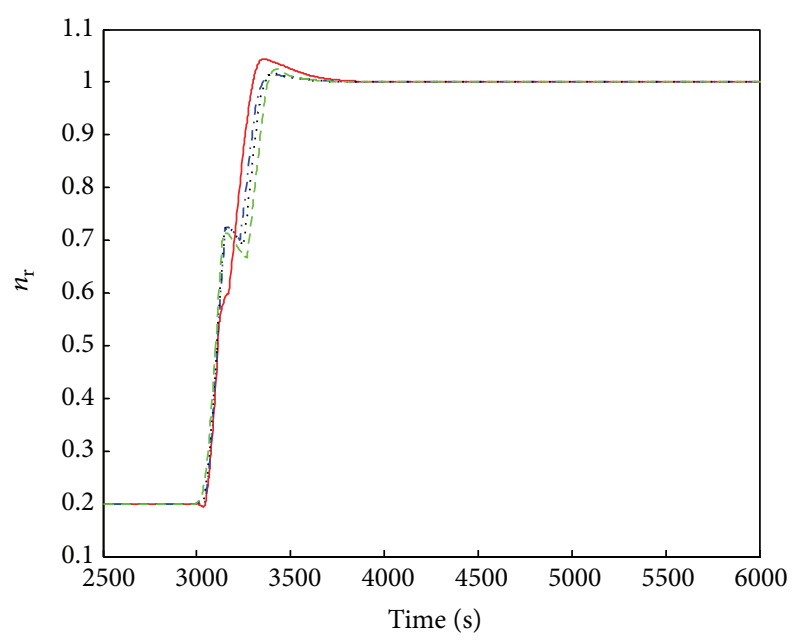

(a)

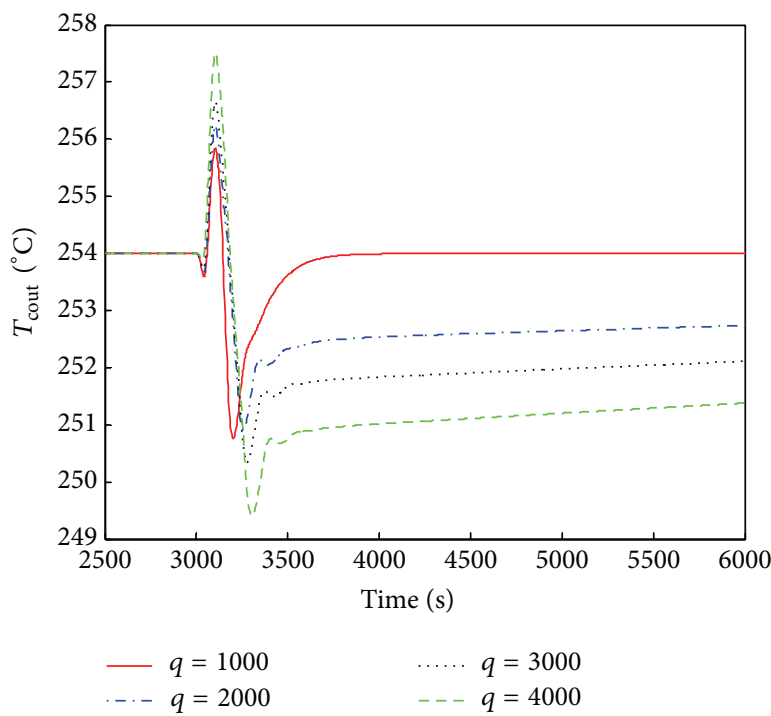

(c)

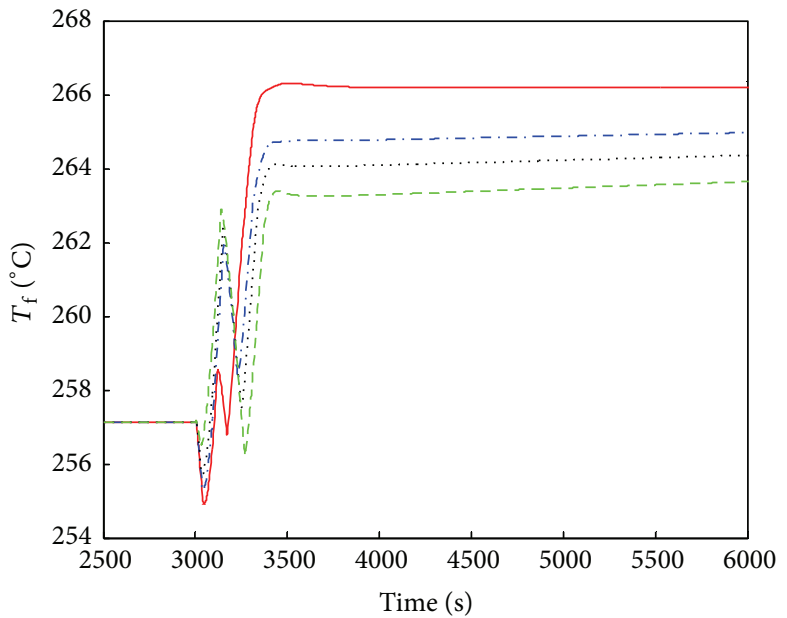

(b)

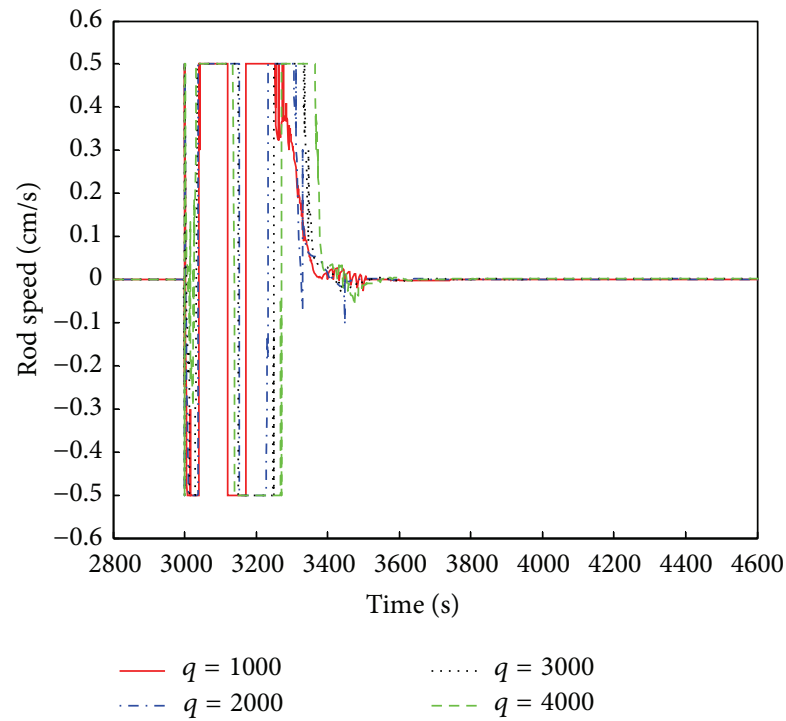

(d)

FIgURE 4: Simulation results in Case A(2).

performance of the key process variables deteriorates. The reason is given as follows. Based on (46), it is so easy to see that if $q$ is larger, then the weight of $V_{1}$ in Lyapunov function $V_{2}$ is smaller. This induces a worse dynamic performance with a larger $q$. There even exist static control errors of both the fuel and coolant temperatures when $q$ is large enough. Therefore, in the practical engineering, we should choose a larger $k_{\mathrm{f}}$ and a smaller $q$ to guarantee the load following performance.

In case of power drop, the stepdown of the load signal causes the rapid increase of $\delta n_{\mathrm{r}}$ which results in the generation of a negative rod speed signal. The insertion of control rods then causes the decreases of both the nuclear power. Similarly in the case of load lift, the total closed-loop system enters into a steady state if the reactivity given by the control rods cancels that induced by the temperature feedback effect.

From Figure 5, it is easy to see that $k_{\mathrm{f}}$ is larger, the transition time of the nuclear power, average fuel temperature, and the outlet coolant temperature are smaller. The reason is similar to that in the case of load lift. Actually, a larger $k_{\mathrm{f}}$ leads to a higher weight of shifted-ectropy $\zeta_{\mathrm{T}}$ in Lyapunov function $V_{1}$, which induces the temperatures of the fuel and the coolant converges more quickly. Faster convergence in both fuel and coolant temperatures weakens their influence on the dynamic response of nuclear power through reactivity feedback effect, and we can see from Figure 5(a) that the transition time of the nuclear power is smaller and $k_{\mathrm{f}}$ is larger. Moreover, if $k_{\mathrm{f}}$ is enough high, we can see that there are larger overshoots of both the fuel and coolant temperatures, this is caused by the stepdown of the load signal which induce the rapid variations in $\delta T_{\text {cav }}$. Then, feeding back this signal through a higher gain leads to a larger overshoot. Though the overshoots are larger when $k_{\mathrm{f}}$ is larger, it is still acceptable.

From Figure 6, it is clear that $q$ is larger, and the dynamic performance of the key process variables is worse. There are 


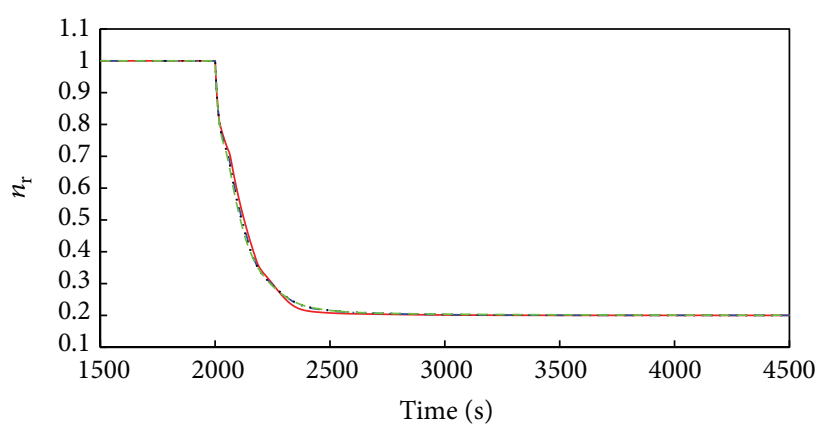

(a)

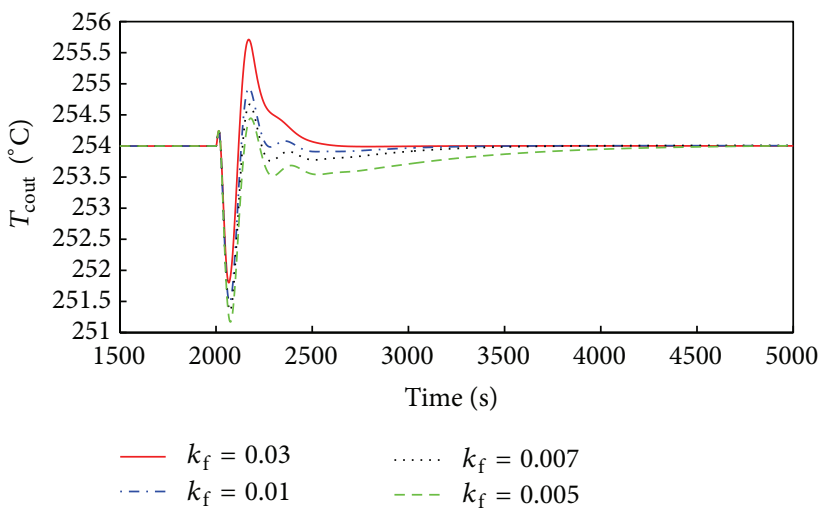

(c)

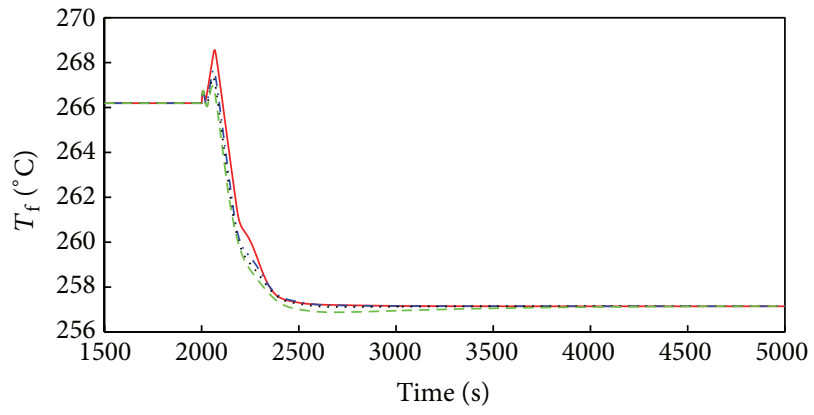

(b)

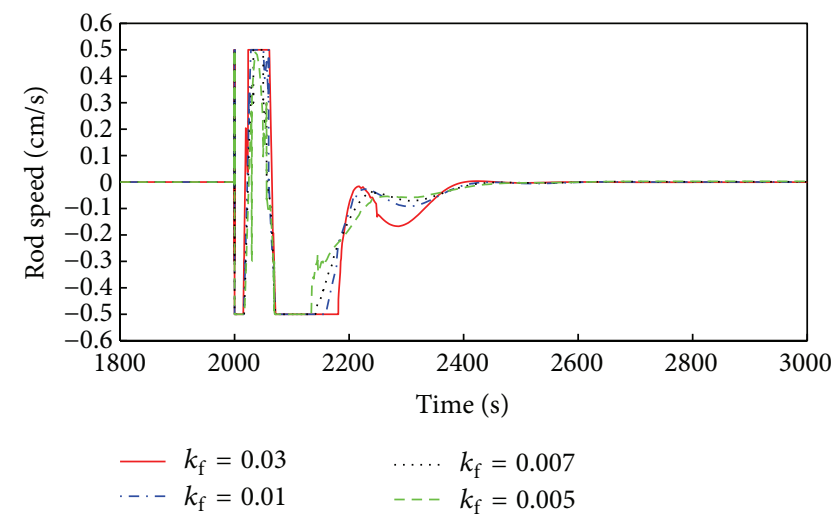

(d)

Figure 5: Simulation results in Case B(1).

even static control errors of the fuel and coolant temperatures if $q$ is large enough. Similar to the case of load lift, if $q$ is larger, then the weight of $V_{1}$ in $V_{2}$ is smaller, which induces a worse dynamic performance.

Finally, from the above analysis and discussion, we can see that nonlinear dynamic output-feedback power-level control law (78) guarantees globally asymptotic closed-loop stability and provides satisfactory load following performance by properly choosing the controller parameters. Due to the integration term induced by adaption mechanism, this nonlinear adaptive controller provides a high regulation performance. Based on (78), we can see that mathematic operations in this new control strategy are also addition, minus, proportional multiplication, differentiation, and integration, which is no more than those of the classical PID control. This also leads to the easy implementation of this control law in digital control system platforms. Moreover, it is worth to be noted that the power-level control strategy given in this paper is only for normal power operation of the NHR and NOT for reactor startup.

\section{Conclusion}

Nuclear heating reactor (NHR) is a small reactor with many advanced safety features and has a promising future in the fields of district heating, seawater desalination, and electricity production. It is so clear that the NHR dynamics has the features of high nonlinearity and uncertainty, which leads to the need of developing nonlinear adaptive power-level control. In this paper, a novel nonlinear adaptive powerlevel control strategy is established based upon the physically based control design approach. It has already been proved theoretically that this newly build controller guarantees globally asymptotic closed-loop stability and satisfactory load following performance. This new control law is then applied to the power-level control of a nuclear heating reactor. Numerical simulation results show not only the feasibility of this controller but also the relationship between the performance and the tuning parameters. This new nonlinear adaptive dynamic output-feedback power-level regulator can be easily implemented on those digital control system platforms. Finally, since the NHR is essentially a kind of PWR, the results in this paper can be directly applied to the power-level control of PWRs. The future work is to design a more powerful adaptive dynamic output-feedback powerlevel control law based on artificial neural networks [32] or fuzzy sets [33].

\section{Acknowledgments}

This work is jointly supported by the Natural Science Foundation (NSFC) of China (Grant no. 61004016), Tsinghua University Initiative Scientific Research Program (Grant no. 20121087992), and National S\&T Major Project (Grant no. ZX06901). The author would like also to thank Professor 


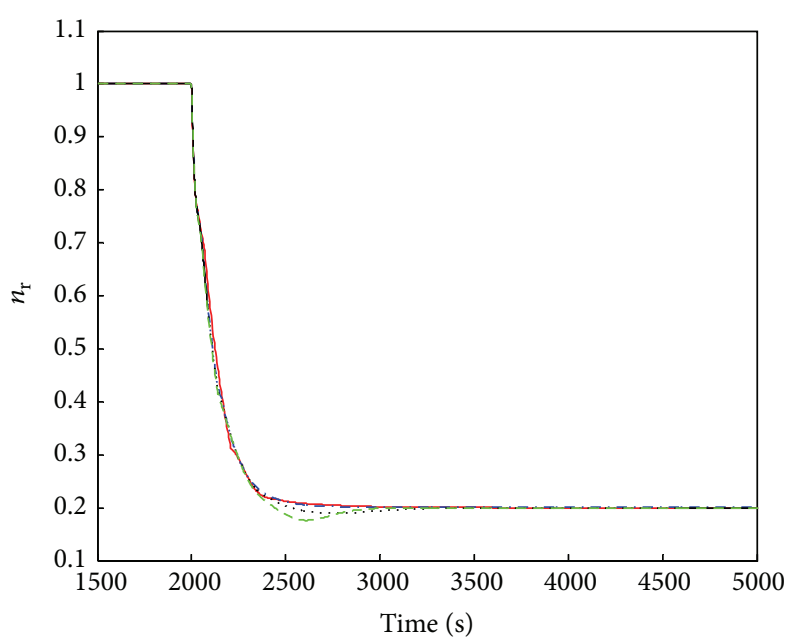

(a)

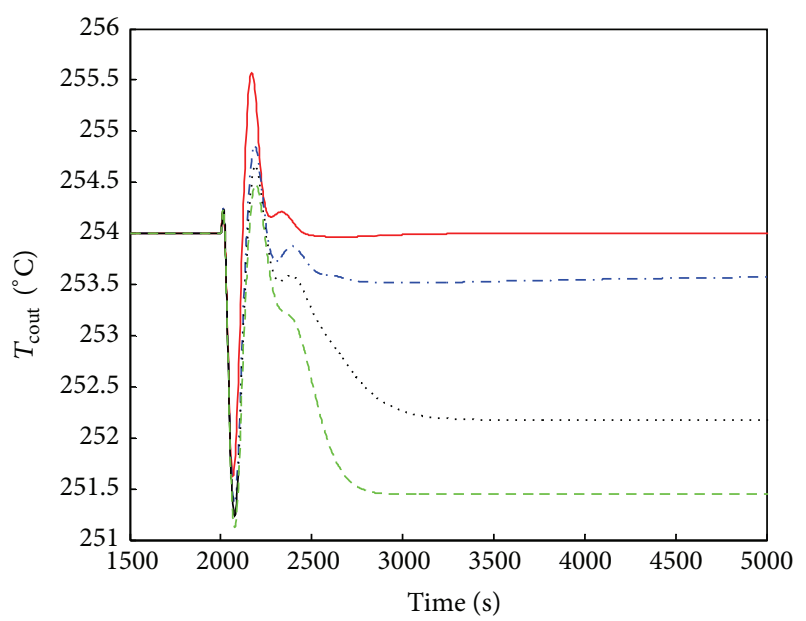

$q=3000$

-.. $q=4000$ $\begin{aligned} \cdots & q \\ \cdots & 5000 \\ ---q & =6000\end{aligned}$

(c)

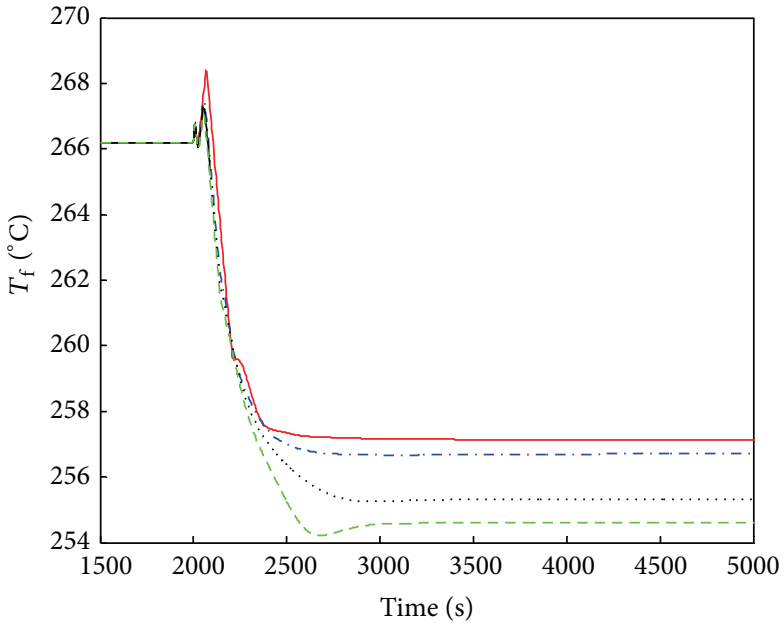

(b)

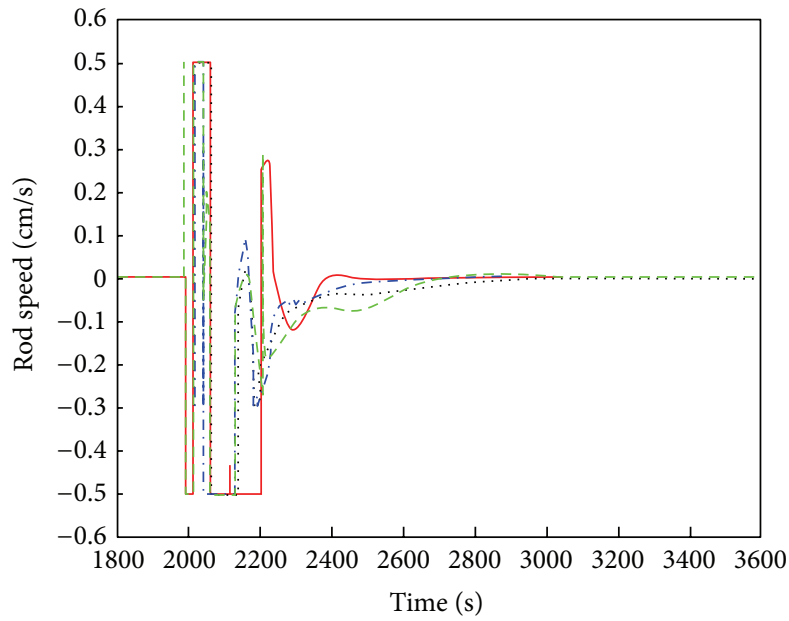

$\begin{aligned}-q & =3000 \\ --q & =4000\end{aligned}$

… $q=5000$

$---q=6000$

(d)

Figure 6: Simulation results in Case B(2).

Huang Xiao-Jin deeply for valuable discussions and constructive suggestions.

\section{References}

[1] W. Zheng, D. Wang, J. Lin, D. Dong, C. Ma, and Y. Wu, "Nuclear heating reactor, a safe, clean and economic energy source," in Potential of Small Nuclear Reactors for Future Clean and Safe Energy Source, H. Sekimoto, Ed., pp. 359-366, Elsevier, New York, NY, USA, 1992.

[2] D. Wang, C. Ma, D. Dong, and J. Lin, "Chinese nuclear heating test reactor and demonstration plant," Nuclear Engineering and Design, vol. 136, no. 1-2, pp. 91-98, 1992.

[3] D. Wang, D. Zhang, D. Dong et al., "Experimental study and operation experiences of the $5 \mathrm{MW}$ nuclear heating reactor," Nuclear Engineering and Design, vol. 143, no. 1, pp. 9-18, 1993.

[4] D. Wang, "The design characteristics and construction experiences of the $5 \mathrm{MWt}$ nuclear heating reactor," Nuclear Engineering and Design, vol. 143, no. 1, pp. 19-24, 1993.
[5] D. Wang, Z. Gao, and W. Zheng, "Technical design features and safety analysis of the $200 \mathrm{MWt}$ nuclear heating reactor," Nuclear Engineering and Design, vol. 143, no. 1, pp. 1-7, 1993.

[6] D. Wang, D. Dong, W. Zheng, D. Zhang, and L. Wang, "The $200 \mathrm{MW}$ nuclear heating reactor and its possible application in seawater desalination," Desalination, vol. 99 , no. 2-3, pp. 383399, 1994.

[7] S. Wu and W. Zheng, "Coupling of nuclear heating reactor with desalination process," Desalination, vol. 142, no. 2, pp. 187-193, 2002.

[8] S. Wu and Z. Zhang, "An approach to improve the economy of desalination plants with a nuclear heating reactor by coupling with hybrid technologies," Desalination, vol. 155, no. 2, pp. 179$185,2003$.

[9] R. M. Edwards, K. Y. Lee, and M. A. Schultz, "State feedback assisted classical control. An incremental approach to control modernization of existing and future nuclear reactors and power plants," Nuclear Technology, vol. 92, no. 2, pp. 167-185, 1990. 
[10] A. Ben-Abdennour, R. M. Edwards, and K. Y. Lee, "LQR/LTR robust control of nuclear reactors with improved temperature performance," IEEE Transactions on Nuclear Science, vol. 39, no. 6, pp. 2286-2294, 1992.

[11] H. Arab-Alibeik and S. Setayeshi, "Improved temperature control of a PWR nuclear reactor using an LQG/LTR based controller," IEEE Transactions on Nuclear Science, vol. 50, no. 2, pp. 211-218, 2003.

[12] Y. B. Shtessel, "Sliding mode control of the space nuclear reactor system," IEEE Transactions on Aerospace and Electronic Systems, vol. 34, no. 2, pp. 579-589, 1998.

[13] Z. Dong, "Nonlinear state-feedback dissipation power level control for nuclear reactors," IEEE Transactions on Nuclear Science, vol. 58, no. 1, pp. 241-257, 2011.

[14] P. Kokotović, “The joy of feedback," IEEE Control Systems, vol. 12, no. 3, pp. 7-17, 1992.

[15] Z. Dong, J. Feng, X. Huang, and L. Zhang, "Dissipation-based high gain filter for monitoring nuclear reactors," IEEE Transactions on Nuclear Science, vol. 57, no. 1, pp. 328-339, 2010.

[16] Z. Dong, X. Huang, and L. Zhang, "Output-feedback loadfollowing control of nuclear reactors based on a dissipative high gain filter," Nuclear Engineering and Design, vol. 241, no. 12, pp. 4783-4793, 2011.

[17] B. M. Maschke, R. Ortega, and A. J. van der Schaft, "Energybased Lyapunov functions for forced Hamiltonian systems with dissipation," IEEE Transactions on Automatic Control, vol. 45, no. 8, pp. 1498-1502, 2000.

[18] R. Ortega, A. van der Schaft, B. M. Maschke, and G. Escobar, "Interconnection and damping assignment passivity-based control of port-controlled Hamiltonian systems," Automatica, vol. 38 , no. 4 , pp. 585-596, 2002.

[19] R. Ortega, A. van der Schaft, F. Castaños, and A. Astolfi, "Control by interconnection and standard passivity-based control of port-Hamiltonian systems," IEEE Transactions on Automatic Control, vol. 53, no. 11, pp. 2527-2542, 2008.

[20] Z. Dong, "Self-stability analysis of MHTGRs: a shifted-ectropy based approach," Nuclear Engineering and Design, vol. 248, pp. 137-148, 2012.

[21] Z. Dong, "Physically-based power-level control for modular high temperature gas-cooled reactors," IEEE Transactions on Nuclear Science, vol. 59, no. 5, pp. 2531-2548, 2012.

[22] J. Fu, "Extended backstepping approach for a class of non-linear systems in generalised output feedback canonical form," IET Control Theory and Applications, vol. 3, no. 8, pp. 1023-1032, 2009.

[23] Z. J. Yang, Y. Fukushima, S. Kanae, and K. Wada, "Robust nonlinear output-feedback control of a magnetic levitation system by K-filter approach," IET Control Theory and Applications, vol. 3, no. 7, pp. 852-864, 2009.

[24] W. MacKunis, Z. D. Wilcox, M. K. Kaiser, and W. E. Dixon, "Global adaptive output feedback tracking control of an unmanned aerial vehicle," IEEE Transactions on Control Systems Technology, vol. 18, no. 6, pp. 1390-1397, 2010.

[25] D. Xu and J. Huang, "Robust adaptive control of a class of nonlinear systems and its applications," IEEE Transactions on Circuits and Systems I, vol. 57, no. 3, pp. 691-702, 2010.

[26] B. Yao, C. Hu, L. Lu, and Q. Wang, "Adaptive robust precision motion control of a high-speed industrial gantry with cogging force compensations," IEEE Transactions on Control Systems Technology, vol. 19, no. 5, pp. 1149-1159, 2011.
[27] M. G. Park and N. Z. Cho, "Time-optimal control of nuclear reactor power with adaptive proportional-integral-feedforward gains," IEEE Transactions on Nuclear Science, vol. 40, no. 3, pp. 266-270, 1993.

[28] H. Arab-Alibeik and S. Setayeshi, "Adaptive control of a PWR core power using neural networks," Annals of Nuclear Energy, vol. 32, no. 6, pp. 588-605, 2005.

[29] Z. Dong, "Nonlinear adaptive power-level control for modular high temperature gas-cooled reactors," IEEE Transactions on Nuclear Science, vol. 60, no. 2, pp. 1332-1345, 2013.

[30] Z. Dong, X. Huang, J. Feng, and L. Zhang, "Dynamic model for control system design and simulation of a low temperature nuclear reactor," Nuclear Engineering and Design, vol. 239, no. 10, pp. 2141-2151, 2009.

[31] Z. Dong, X. Huang, and J. Feng, "Water-level control for the Utube steam generator of nuclear power plants based on output feedback dissipation," IEEE Transactions on Nuclear Science, vol. 56, no. 3, pp. 1600-1612, 2009.

[32] J. Na, X. Ren, and D. Zheng, "Adaptive control for nonlinear pure-feedback systems with high-order sliding mode observer," IEEE Transactions on Networks and Learning Systems, vol. 24, no. 3, pp. 370-382, 2013.

[33] Y. J. Liu, S. Tong, and C. L. P. Chen, "Adaptive fuzzy control via observer design for uncertain nonlinear systems with unmodeled dynamics," IEEE Transactions on Fuzzy Systems, vol. 21, no. 2, pp. 275-288, 2013. 


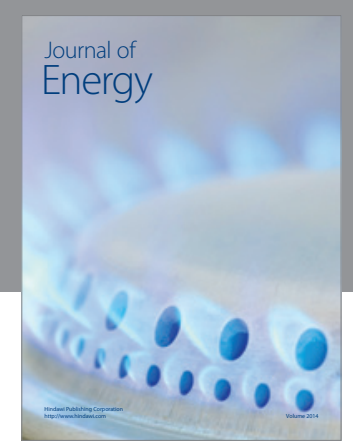

Journal of

Industrial Engineering
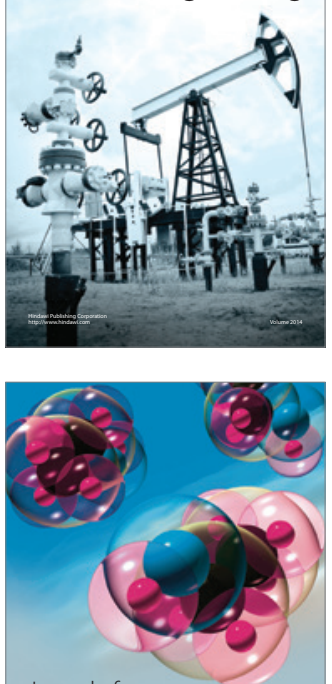

Fuels
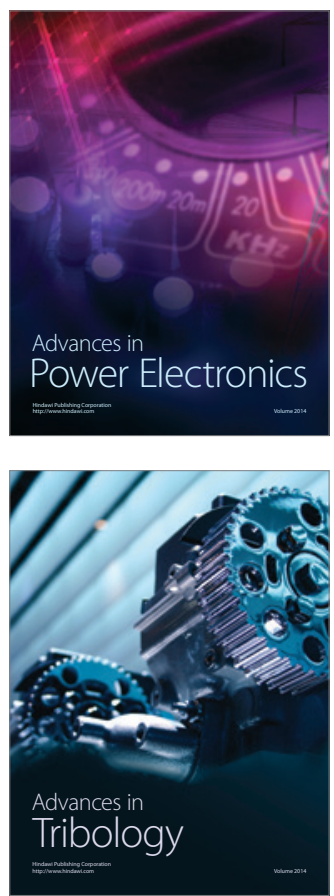

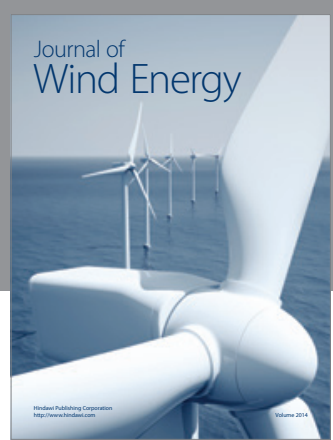

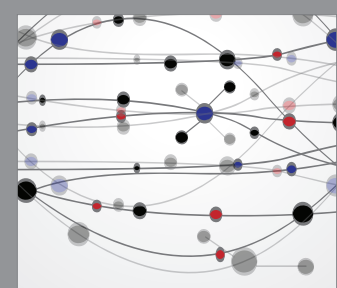

The Scientific World Journal

Submit your manuscripts at http://www.hindawi.com

Journal of

Structures
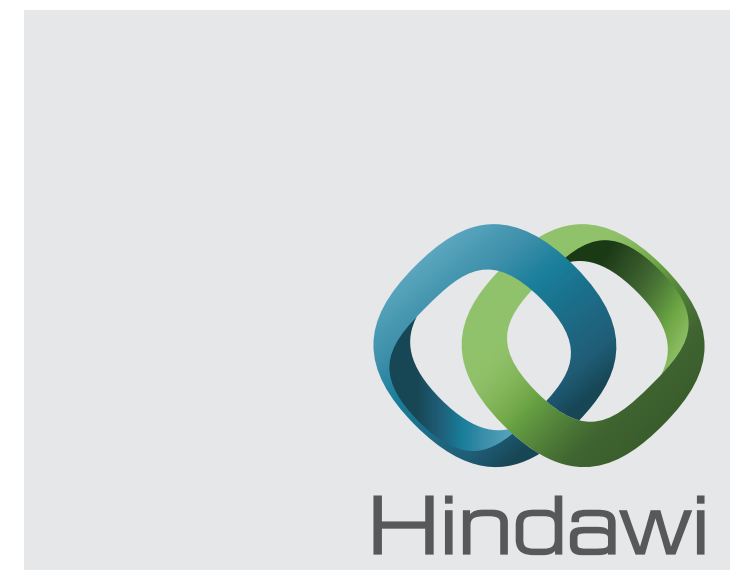

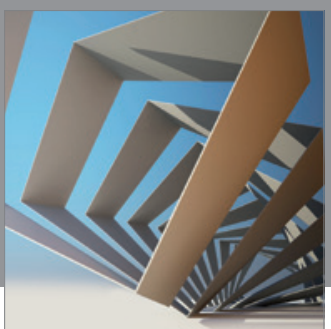

Rotating

Machinery
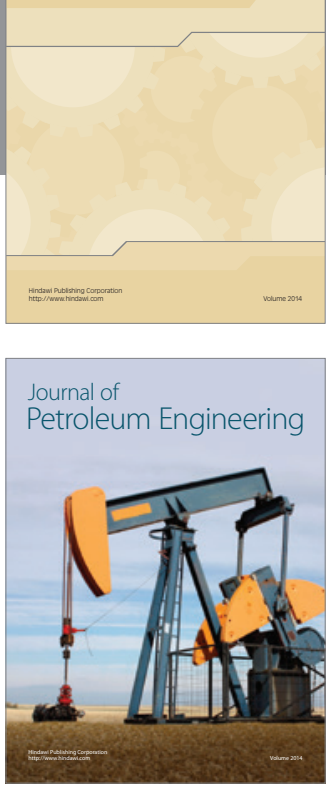

Journal of

Solar Energy
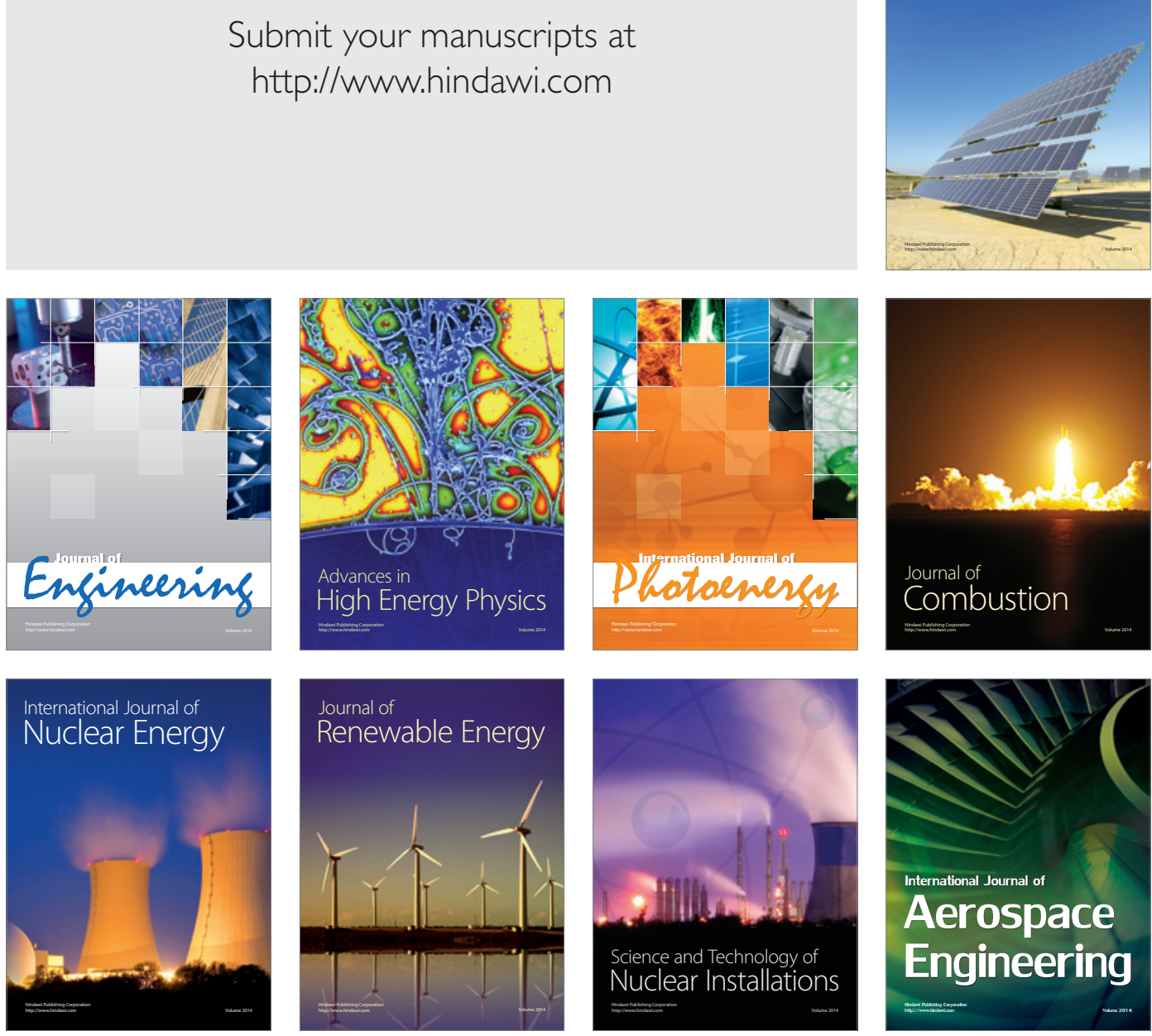